Spring 4-23-2020

\title{
Enhancing Engagement in Older Adults with Alzheimer's Disease at a Reminiscencce Therapy Adult Day Center
}

Kendra C. Gillio

University of St. Augustine for Health Sciences

DOI: https://doi.org/10.46409/sr.ZHFN3134

Follow this and additional works at: https://soar.usa.edu/capstones

Part of the Nervous System Diseases Commons, and the Occupational Therapy Commons

\section{Recommended Citation}

Gillio, K. C. (2020). Enhancing Engagement in Older Adults with Alzheimer's Disease at a Reminiscencce Therapy Adult Day Center. [Doctoral project, University of St Augustine for Health Sciences]. SOAR @ USA: Student Capstone Projects Collection. https://doi.org/10.46409/sr.ZHFN3134

This Capstone is brought to you for free and open access by the Student Research at SOAR @ USA. It has been accepted for inclusion in Student Capstone Projects by an authorized administrator of SOAR @ USA. For more information, please contact soar@usa.edu, erobinson@usa.edu. 
Running head: ENHANCING ENGAGEMENT IN OLDER ADULTS WITH ALZHEIMER'S 1

ENHANCING ENGAGEMENT IN OLDER ADULTS WITH ALZHEIMER'S DISEASE AT A REMINISCENCE THERAPY ADULT DAY CENTER

by

Kendra C Gillio, OTDS

\begin{abstract}
A Capstone Presented in Partial Fulfillment of the Requirements for the Degree of DOCTOR OF OCCUPATIONAL THERAPY University of St. Augustine for Health Sciences
\end{abstract} April, 2020 
ENHANCING ENGAGEMENT IN OLDER ADULTS WITH ALZHEIMER'S DISEASE AT A REMINISCENCE THERAPY ADULT DAY CENTER

by

Kendra C Gillio, OTDS

has been approved

April, 2020

APPROVED:

Susan MacDermott, OTD, OTR/L, Doctoral Coordinator

Becki Cohill, OTD, OTR/L, Doctoral Coordinator

Erin Schwier, EdD, OTD, OTR/L, Program Director

ACCEPTED AND SIGNED:

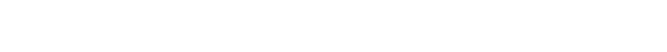

OTD, OTR/L

OTD, OTR/L

$c=U S$
Date: 2020.05 .06 13:44:27 -07'00'

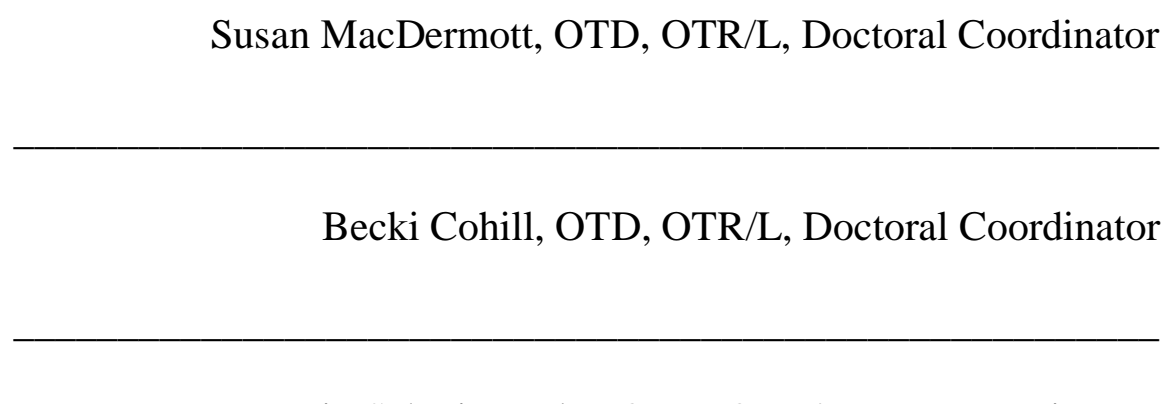

Erin Schwier, EdD, OTD, OTR/L, Program Director 


\section{Table of Contents}

Chapter I. Introduction



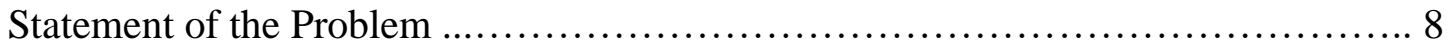

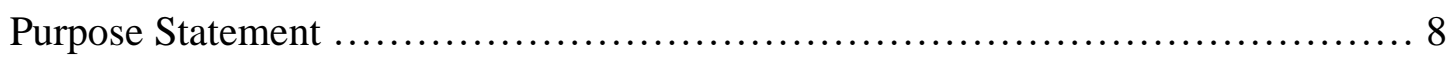

Rationale for Proposed Project ........................................... 9

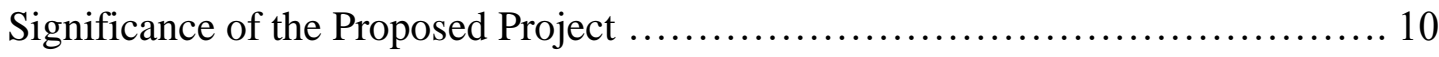

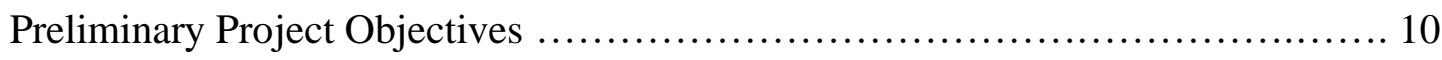

Assumptions, Limitations and Delimitations ............................... 11

Chapter II. Literature Review

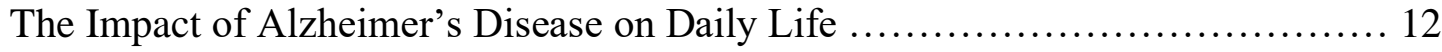

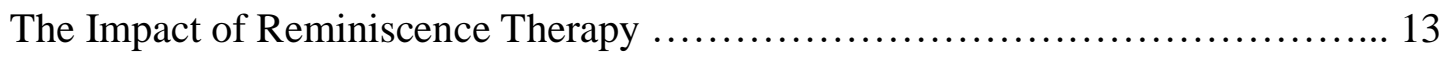

Occupational Therapy's Role for Individuals with Alzheimer's Disease ........... 13

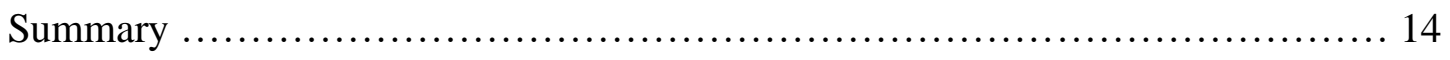

Chapter III. Project Description

Methods ................................................................. 14

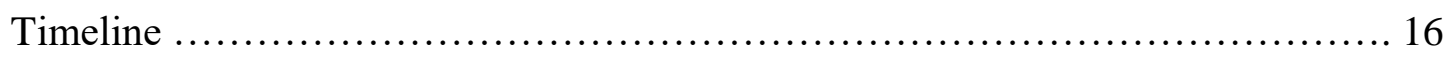

Chapter IV. Results and Analysis



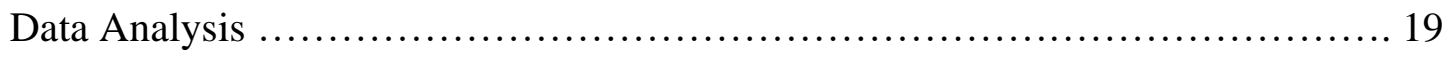

Glenner Town Square Activity Recommendations ........................... 29

Exercise as an Occupation ............................................. 29

Visual, Auditory, and Kinesthetic Learners ............................... 30 


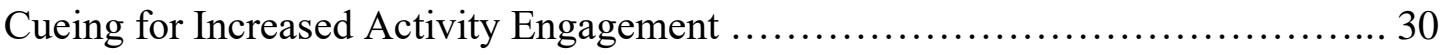

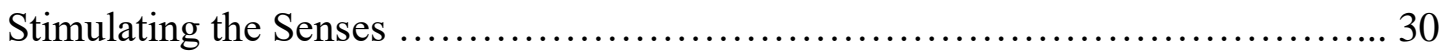

Partner or Small Group Activities ........................................ 31

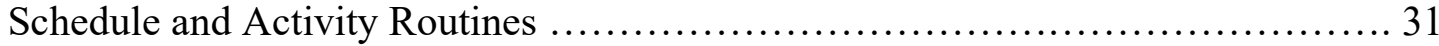

Table Top Activities to Spark Social Participation ........................... 31

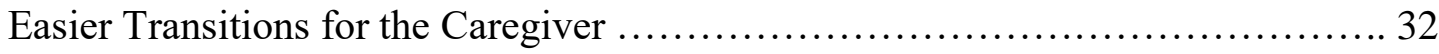

"Take Home Reports" for the Caregiver ...................................... 32

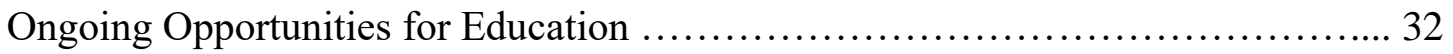

Chapter V. Summary, Discussion and Conclusion

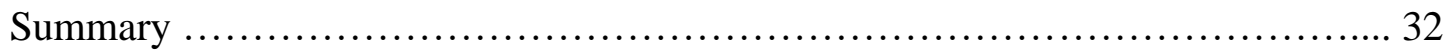

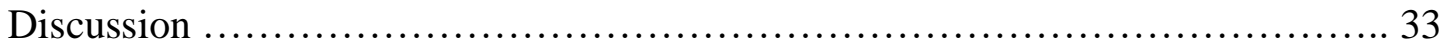

Limitations and Barriers ................................................ 34

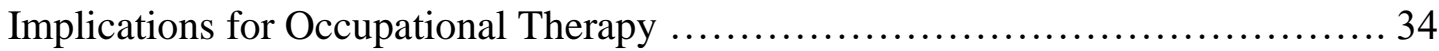

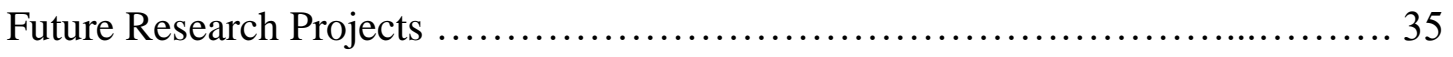

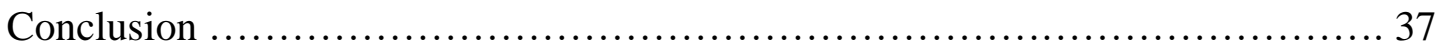

References

References ......................................................... 39

Appendices

Appendix A. Glenner Town Square Activity List ........................... 48

Appendix B. Glenner Town Square Staff Survey Questions ..................... 50

Appendix C. Caregiver Semi-Structured Interview Questions ................... 51

Appendix D. Exercise as an Occupation Activity ............................. 52

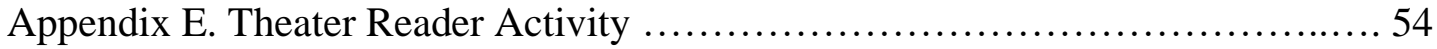


Appendix F. Cueing Techniques for Increased Activity Engagement ............... 58



Appendix H. Partner or Small Group Activities .................................. 61

Appendix I. Schedule and Activity Routine …............................... 68

Appendix J. Table Top Social Participation Activities ............................. 69

Appendix K. Caregiver Take Home Report ................................... 70

Appendix L. Ongoing Educational Opportunities ................................ 71 
ENHANCING ENGAGEMENT IN OLDER ADULTS WITH ALZHEIMER'S 6

Enhancing Engagement in Older Adults with Alzheimer's Disease at a Reminiscence Therapy Adult Day Center

\section{Background}

Alzheimer's disease is a degenerative form of dementia, which can impair an individual's executive functioning, orientation, and memory; ultimately leading to mood and behavior changes (Alzate, 2018). Alzheimer's disease is the most common form of dementia, affecting approximately $60 \%$ to $70 \%$ of the older adult population aged 65 and older (Santos da Silva, de Oliveira Alves, Barros Leite Slagueiro \& Bezerra Barbosa, 2018). Currently the number of individuals with dementia is estimated at approximately 50 million people worldwide and is expected to climb to 152 million people by the year 2050 (Rathbone, et. al, 2019). Damage to the brain develops slowly; about 10 to 20 years prior to the presentation of signs and symptoms of Alzheimer's disease, and the individual progressively declines over time, with death occurring approximately 7 to 10 years after onset (Alzate, 2018). While there is no current cure for Alzheimer's disease, treatments to temporarily slow the worsening of symptoms are available to improve quality of life, as research continues (Pedroso, et al., 2018).

Current treatments include pharmacological options and the use of natural plant-based herbs to help aid in the management of symptoms associated with Alzheimer's disease (Ayyalasomayajula \& Suresh, 2018). A downfall to both treatments is the approach only targets the individual, rather than encompassing a combination of both the individual and their environment. One of the more recent treatments of Alzheimer's disease is the use of reminiscence therapy, which directly addresses the surrounding environment of the individual (Swann, 2013). Reminiscence therapy prompts an individual's memory by stimulating their 
senses - sight, smell, hearing, taste, and touch, and provides an opportunity for them to revisit and relive their past through their surrounding environment (Swann, 2013). Reviewing and revisiting past environments and experiences is a natural part of life that can promote positive emotions and enhance an individual's ability to work through present situations (Blake, 2013). Reminiscence therapy encourages this process for individuals with Alzheimer's disease to improve cognitive functions, depressive symptoms, and quality of life (Lök, Bademli, \& SelçukTosun, 2018).

Occupational therapy also has a history of helping individuals with cognitive disabilities, alongside their caregivers, to adapt the environment to maximize engagement in meaningful activities (i.e. occupations), promote safety awareness, and enhance quality of life (American Occupational Therapy Association, 2011). A key focus of occupational therapy for individuals with Alzheimer's disease is their ability to engage in meaningful occupations, quality of life, and social participation; in order to optimize occupational performance (Letts, et. al, 2011). Occupational therapy refers to any meaningful activity that "occupies" your time, including basic self-care, fundamental community tasks, or leisure and social activities (Corvol, Netter, Campeon, \& Somme, 2018). The American Occupational Therapy Association's vision for 2025 is to "maximize health, well-being, and quality of life for all people, populations, and communities through effective solutions that facilitate participation in everyday living" (American Occupational Therapy Association, 2016, para. 1). Yet limited studies have explored the relationship between occupations, self-care, memory, and executive functioning in individuals with Alzheimer's disease (Baum, 2011). 
ENHANCING ENGAGEMENT IN OLDER ADULTS WITH ALZHEIMER'S 8

\section{Statement of the Problem}

Activities of daily living (ADL's), instrumental activities of daily living (IADL's), leisure activities, and social activities are reported as problematic areas for individuals with mild to moderate dementia or Alzheimer's disease (Padilla, 2011). Intervention approaches such as verbal prompting and cueing, activity and environmental modification, and the use of adaptive equipment have been used to initiate activities and promote independence for individuals with Alzheimer's disease (Padilla, 2011). Limited evidence-based research supporting these approaches exists, often reporting on small sample sizes and relying only on subjective or observational outcome measures (Padilla, 2011). The use of reminiscence therapy is a more recent approach to the treatment of Alzheimer's disease symptoms, by which individuals have the opportunity to recall the past as it relates to their surrounding stimuli (Swann, 2013). Individuals with Alzheimer's disease are typically able to recall events from their earlier life and not always from the same day, and the use of reminiscence therapy is suggested to positively impact memory and cognition (Blake, 2013). Reminiscence therapy shows the potential to improve occupational functioning for an individual with Alzheimer's disease, however occupational therapy is not currently involved.

\section{Purpose Statement}

Alzheimer's disease has yet to reach an effective cure, but treatments such as the ones listed above have been used to slow the progression of symptoms. However, based on the recent literature search, limited evidence-based research exists regarding the effectiveness of reminiscence therapy and its impact on occupational performance for individuals with Alzheimer's disease. The purpose of completing a needs assessment and then providing program recommendations to enhance engagement in current activities at an adult day care reminiscence 
ENHANCING ENGAGEMENT IN OLDER ADULTS WITH ALZHEIMER'S 9

therapy program for individuals with Alzheimer's disease is to provide evidence-based treatment focused on enhancing memory, cognition, activity engagement and social participation.

\section{Rationale for Proposed Project}

This project will be developed using Allen's Cognitive Disability frame of reference (Allen, 1992). The Allen's Cognitive Disability frame of reference focuses on the role of cognition as it relates to habits and routines, physical and social contexts, and activity demand (Allen, 1992). Cognitive limitations and symptoms associated with Alzheimer's disease can create challenges impacting independence in daily occupations, safety, mobility, and social engagement (Allen, 1992). This project will use task analysis through the use a needs assessment in order to determine the appropriate level of complexity of a program activity for the Alzheimer's disease population, and then suggest program recommendations focused on memory, cognition, activity participation, and social engagement through the use of occupationbased activities in a reminiscence therapy environment (Allen, 1992). The six levels associated with Allen's Cognitive Disability frame of reference include automatic actions, postural actions, manual actions, goal-directed actions, exploratory actions, and planned actions (Allen, 1992). Identifying the appropriate cognitive level of individuals with Alzheimer's disease prior to the start of the program, will be important to providing the just right challenge, where the task demand is matched to the individual's current capacity to function (Allen, 1992). As it pertains to Allen's Cognitive Disability frame of reference, occupational engagement through the use of instructions, cues, assistance, and environmental adaptation, will be the primary approach to treatment for this reminiscence therapy program (Allen, 1992). 


\section{Significance of the Proposed Project}

While there is no current treatment for Alzheimer's disease, enhancing engagement in current activities which focus on the declining function and symptoms, and enhances occupational performance, can potentially change the future of the population. Since the 1980's reminiscence therapy has been one of the most popular forms of treatment for individuals with Alzheimer's disease (Melendez, Torres, Redondo, Mayordromo, \& Sales, 2017). By relating past experiences, facts, or actions from an individual's meaningful memories to a specific stimuli, memory, communication, and cognition may be retained (Melendez et al., 2017). Occupational therapy plays an important role in empowering individuals with Alzheimer's disease to engage in meaningful occupations to enhance quality of life and occupational performance (Hwang, Rivas, Fremming, Rivas \& Crane, 2009). The adaptation of current activities, which focus on, increased engagement, memory, cognition, and social participation, may have the potential to improve the occupational performance of individuals with Alzheimer's disease.

\section{Preliminary Project Objectives}

Preliminary project objectives include the following:

- Observe the current environmental impact and assess activity engagement and social participation at an adult day care reminiscence therapy program for individuals with Alzheimer's disease and dementia.

- Complete a needs assessment in order to identify the activity engagement and social participation needs of individuals with Alzheimer's disease and dementia at an adult day care reminiscence therapy program.

- Identify the approaches for implementation of a reminiscence therapy program, which focus on memory, cognition, and social engagement through a literature search. 
- Identify physical, social, and environmental factors which negatively impact individuals with Alzheimer's disease and dementia.

- Develop and propose program recommendations that will provide suggestions to adapt current activities for the Alzheimer's disease and dementia population, based on data collection from the literature search and clinical observation.

\section{Assumptions, Limitations, and Delimitations}

This project will be based on the assumption that all participants with a medical diagnosis of Alzheimer's disease or dementia have decreased memory, cognition, and social participation, therefore limiting occupational performance (Blake, 2013). This project will also assume that reminiscence therapy will benefit all participants with a medical diagnosis of Alzheimer's disease or dementia. Melendez et al. (2017), reports that reminiscence therapy may improve memory, communication, and cognition for individuals with Alzheimer's disease. It can also be assumed that the current design and activity space or structure of the facility has a needed area of improvement that is not already adapted based on the cognitive levels of the participants. It will also be assumed that the facility will be receptive to activity recommendations or facility adaptations to enhance programing for participants with Alzheimer's disease.

A limitation of this project is the accessibility to the facility staff, caregivers and participants due to their willingness to participate in the study. Also, the length of time to complete the proposed project will limit the ability to observe the implementation of suggested recommendations. Lastly, the recommended adaptations may be a limitation to this project because of feasibility and affordability due to the already implemented environmental designs.

The delimitations of this project will include participants who have a medical diagnosis of Alzheimer's disease or dementia. The information collected for this project will be specific to 
this population and the components that encompass their daily lives; which may include their caregivers and the staff at the reminiscence facility.

\section{Chapter II. Literature Review}

The purpose of this literature review is to explore the role of occupational therapy with the Alzheimer's disease population within a reminiscence therapy setting. It will review evidence that supports the use of occupational therapy and reminiscence therapy, separately, with the Alzheimer's disease and dementia population and examine the effects on daily life, cognition, memory, social participation, and occupational performance. Future program development recommendations will be made to the facility based on suggestions from the literature.

\section{The Impact of Alzheimer's Disease on Daily Life}

The effects of Alzheimer's disease on daily life can be identified by common themes across a widespread population, including decreased executive functioning, memory and orientation, decreased social participation, and decreased occupational performance or quality of life (Alzate, 2018). According to Huang et al., a decrease in cognitive function, and an increase in depressive symptoms are common in older adults with Alzheimer's disease (2015). Winbald et.al describe a decrease in cognitive domains, daily functioning, and social interactions for individuals with Alzheimer's disease, which also directly affect the daily lives of their families and caregivers (2016). Santos da Silva et al. (2018), review barriers to success for individuals with Alzheimer's disease, which include lack of professional, social, and family regarding activities of daily living; and lack of caregiver knowledge regarding the disease itself. Edwards (2015) describes the negative physical, mental, and financial impact on those providing care for individuals with Alzheimer's disease, noting the influence on overall health and well-being of 
the caregiver. Raggi, Tasca, Panerai, Neri, and Ferri (2015) identify common concerns of families and caregivers for individuals living with Alzheimer's disease, including caregiver burden and associated coping strategies.

\section{The Impact of Reminiscence Therapy}

Reminiscence therapy is a non-pharmacological approach to the long-term care of individuals with Alzheimer's disease, focused on exploring its effects on quality of life and caregiver burden (Fletcher \& Eckberg, 2014). Amieva and Dartigues (2013) describe reminiscence therapy as a way to tap into an individual's "preserved store of remote memories". A study by Cotelli, Manenti, and Zanetti (2012) reviews the ability of reminiscence therapy to improve mood and cognitive abilities of individuals with Alzheimer's disease. Woods, Aguirre, Spector and Orrell (2012) report statistically significant results in regards to their study on improved cognition, mood, and general behavioral function for individuals with Alzheimer's disease. Yet, limited evidence supporting the effectiveness of Alzheimer's disease rehabilitation exists according to Yamagami, Oosawa, Ito, and Yamaguchi (2007).

\section{Occupational Therapy's Role for Individuals with Alzheimer's Disease}

Smallfield and Heckenlaible (2017) explore the role of occupational therapy and its focus on establishing, modifying and maintaining occupations for adults with Alzheimer's disease. Padilla (2011) reviews the effectiveness of interventions designed to modify the activity demands of occupations, such as self-care, work, leisure, and social participation. Walker, Allen, Koch, Sprehe \& Webber (2017) support engagement in occupations, and enhancing occupational performance through the use of environmental modifications as a review of strategies to improve quality of life of individuals with Alzheimer's disease. Lanzoni et al. (2018) discuss the use of 'tailored activity programs' and prescribed activities used by occupational therapists to aid in the 
slowing of, or reduction in occurrence of unwanted behaviors associated with Alzheimer's disease. They also review previous studies which have shown how community-based occupational therapy promotes improvement in functional independence and autonomy, and a decrease in overall burden of care, for individuals with Alzheimer's disease (Lanzoni et al., 2018).

\section{Summary}

The literature review shows individuals with Alzheimer's disease have a major decline in memory, social participation and activity engagement, which limits their overall occupational performance and quality of life (Alzate, 2018). Reminiscence therapy is one approach to treatment for these individuals, focused on retrieving past memories stimulated by the surrounding environment (Fletcher \& Eckberg, 2014). Occupational therapy research has also shown that an increase in activity engagement can have a positive impact on individuals with Alzheimer's disease or dementia, resulting in increased social behavior, communication, happiness, and quality of life; and a decrease in inappropriate, maladaptive, aggressive and passive behaviors (Boyden, Miltenberger, and Novotny, 2020). Engaging an older adult with Alzheimer's disease or dementia in meaningful activities has been shown to increase positive emotions, improve activities of daily living, and quality of life (Engelman, Altus and Mathews, 2013).

\section{Chapter III. Project Description}

\section{Methods}

Qualitative data was gathered for this project through the use of a needs assessment in order to explore activity engagement and social participation needs of the Alzheimer's disease 
and dementia population at Glenner Town Square adult day care facility in Chula Vista, California. This needs assessment included participant, staff, and caregiver observation, survey, and semi-structured interviews. This helped to explore how people perceive their experiences, how people behave, how organizations function, and how relationships are influenced (Teherani, Martimianakis, Stenfors-Hayes, Wadhwa, \& Varpio, 2015). Information gathered was then used to make recommendations to enhance participant engagement in current activities at Glenner Town Square, which focused on activities of daily living, instrumental activities of daily living, leisure activities, and social activities.

Participants for this project were gathered using convenience (i.e. participants who are readily accessible and easily available to participate) (Elfil \& Negida, 2017). The target population was individuals with a medical diagnosis of Alzheimer's disease or dementia, who currently attend Glenner Town Square adult day facility in Chula Vista, California. Participants were recruited with the assistance of the Glenner Town Square program directors, activity coordinators, the on-site nursing staff and the occupational therapist. At the start of the project, the facility staff were introduced to the project procedures and goals and discussed any remaining questions or concerns. Participants and their caregivers were invited to participate in this project (i.e. surveys, interviews, and observation), and asked to provide verbal consent prior to the start.

Information was gathered using surveys, semi-structured interviews, and observation with participants, caregivers, and facility staff. Observation is a fundamental component of assessing the occupational performance of individuals who may be unable to accurately selfreport (MacKenzie and Westwood, 2013). Surveys explore information from a group of individuals on a related topic, with the opportunity to anonymously describe their experiences 
and provide feedback (Ponto, 2015). Semi-structured interviews use a combination of closedended and open-ended questions which provide the opportunity for continued conversation and explanation from both the interviewer and interviewee (Newcomer, 2015). These approaches to data collection were important to understanding the staff, the participant, and their caregiver's current perspective on cognition, memory, social participation, and occupational performance. The staff survey and caregiver semi-structured interview questions can be located in Appendices B and C. Observations were also be used to collect data about program processes, current activities, activity engagement and ongoing occupational performance of participants. Participant observation allows for a snapshot collection of important information on people's behaviors in a natural setting while participating in meaningful activities (Kawulich, 2005).

\section{Timeline}

The duration of the project lasted 18 weeks in total. The first 5 weeks of the project were spent collecting foundational knowledge on current treatments available through observing and

volunteering at outside facilities and sites which offered a wide range of Alzheimer's disease and dementia memory care programs, support groups and activities, including but not limited to reminiscence therapy and occupational therapy. These sites include the Alzheimer's Association, the Institute on Aging, and the Elder Care Alliance. During this time, data was collected via observation of activity engagement, program design and construct, current occupational therapy and reminiscence therapy treatment, and potential barriers to Alzheimer's disease and dementia care.

Then, during weeks 6-9 the student transitioned to Glenner Town Square in Chula Vista, California, to begin observation of the participants' daily rituals, roles, and routines at the adult day center, current activity programing and caregiver support groups. The student volunteered in 
daily activities to build rapport with the participants, caregivers, and staff, in order to continue with gathering information through survey, interview and observation in the following weeks. The student also visited Casa Pacifica adult day center to observe the use of reminiscence therapy during occupational therapy treatments with the Alzheimer's disease and dementia population. The next phase of the project began with recorded surveys and group semi-structured interviews with Glenner Town Square facility staff and caregivers, in order to understand barriers to treatment, caregiver burden, memory and cognition, occupational performance, and social participation. During the remaining weeks of the project the student collaborated with facility staff to identify barriers to treatment and used evidence-based research to make program recommendations on current facility activities. These current activity recommendations were made with a focus on memory and cognition, increased activity engagement, social participation, and occupational performance, on the foundations of occupational therapy in a reminiscence therapy setting for individuals with Alzheimer's disease and dementia. The intended outcome of this project is to determine occupational therapy's role with the Alzheimer's disease and dementia population, and the use of reminiscence therapy, as it relates to memory and cognition, activity engagement, social participation, and occupational performance.

\section{Chapter IV. Results and Analysis}

\section{Results}

Upon completion of the needs assessment at Glenner Town Square, various results outlined the needs of the Alzheimer's disease and dementia population as it relates to reminiscence therapy and occupational therapy. The needs assessment included participant observation, a Glenner Town Square staff survey, and caregiver semi-structured group 
interviews. The purpose of participant observation was to look, listen, and think about what significant details, behaviors, and needs could be identified from observing individuals with Alzheimer's disease or dementia, related to their engagement in activities, their social participation, and their overall occupational performance. The participant observation included observation of approximately 50 to 80 different participants over an eight-week period at Glenner Town Square in Chula Vista, California, while they engaged in group activities and tasks within a reminiscence environment. See Appendix A for a list of the activities observed at Glenner Town Square.

The purpose of the staff survey was to gather feedback from Glenner Town Square staff regarding their daily interaction caring for the participants, leading their daily activities, and understanding how they perceive the activity engagement of the participants. The staff survey included 12 open and close-ended questions focused on the needs, behaviors, activity participation, and social participation of the Alzheimer's disease and dementia population at Glenner Town Square. See Appendix B for a list of the staff survey questions. There were 5 staff respondents to the Glenner Town Square survey.

The purpose of the caregiver semi-structured group interview was to explore the daily experiences of caregivers for individuals with Alzheimer's disease or dementia. The caregiver semi-structured group interview explored the needs of the Alzheimer's disease and dementia population, their experiences, the daily challenges and barriers to caregiving, and approaches or strategies to overcome those challenges. See Appendix C for an overview of the topics and questions covered during the semi-structured group interview. There were 14 caregivers who participated in the semi-structured group interview. 


\section{Data Analysis}

Data analysis for this project consisted of identifying common behaviors, results, and concepts derived from the observational information, surveys, and semi-structured interviews that were conducted.

The results from the needs assessment at Glenner Town Square includes the following: Participant observation: Identifying Glenner Town Square participant behaviors and needs, and their connection to activity engagement. Observation of participant engagement in group activities over the course of eight weeks at Glenner Town square revealed common behaviors and needs that can be inferred of the Alzheimer's disease and dementia population within a reminiscence therapy environment. A list of the group activities observed at Glenner Town Square can be found in Appendix A. An overview of the common behaviors and needs identified, and the connection to activity engagement identified from the participant observation can be found below in Table 1. This observation component of the capstone experience project was important for gathering foundational knowledge of the population, the activities, and the reminiscence environment at Glenner Town Square in order to then make recommendations on how to best adapt the tasks, activities, and environment to benefit the population needs of the participants with Alzheimer's disease and dementia.

Table 1

Participant Observation in Connection to Activity Engagement

\begin{tabular}{c|c|c}
\hline Behavior & Analysis of Observed Behavior & Connection to Activity and \\
& Engagement \\
\hline
\end{tabular}




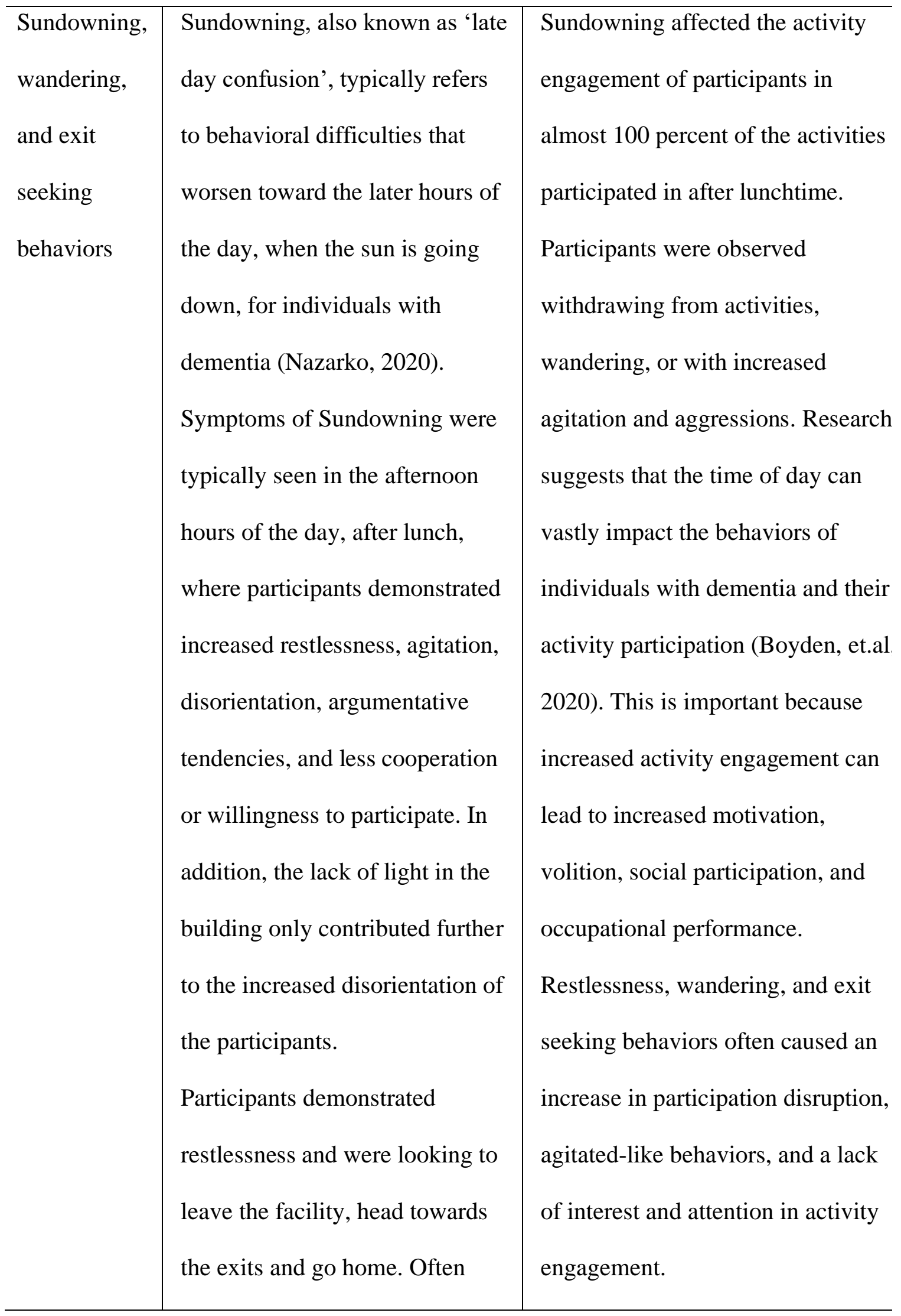




\begin{tabular}{|c|c|c|}
\hline & $\begin{array}{l}\text { asking if their loved one is going } \\
\text { to come and pick them up, and } \\
\text { when they will be there. }\end{array}$ & \\
\hline $\begin{array}{l}\text { Decreases in } \\
\text { activity and } \\
\text { social } \\
\text { participation. }\end{array}$ & $\begin{array}{l}\text { Throughout the day, participants } \\
\text { could be seen withdrawing from } \\
\text { activities, and self-isolating; } \\
\text { ultimately limiting their social } \\
\text { interactions and participation in } \\
\text { group activities. Although they } \\
\text { were physically sitting with their } \\
\text { group, participants could be } \\
\text { found falling asleep or sitting in } \\
\text { silence amongst each other, with } \\
\text { limited communication and } \\
\text { social interaction. Unless direct } \\
\text { social interaction approaches } \\
\text { were used by the participant } \\
\text { assistants to get the participants } \\
\text { withdraw from the activity. } \\
\text { one in the activity or with } \\
\text { to }\end{array}$ & $\begin{array}{l}\text { Research shows that engagement } \\
\text { in leisure and social activities, one } \\
\text { of the major components of a } \\
\text { healthy lifestyle, can have a } \\
\text { positive impact on cognitive } \\
\text { functions for individuals with } \\
\text { dementia (Wang, Xu, and Pei, } \\
\text { 2012). The participant withdrawal } \\
\text { from activities throughout the day } \\
\text { at Glenner Town Square could } \\
\text { have been due to lack of interest, } \\
\text { motivation, volition or cognitive } \\
\text { larger activities. This may have } \\
\text { ability to engage in the level of } \\
\text { activity provided. Groups } \\
\text { typically consisted of } 8 \text { - } 10 \\
\text { participants, but sometimes }\end{array}$ \\
\hline
\end{tabular}




\begin{tabular}{|c|c|c|}
\hline & & $\begin{array}{l}\text { activity engagement and social } \\
\text { participation of the participants. } \\
\text { Smaller group sizes are positively } \\
\text { associated with increased social } \\
\text { interaction (Day, Carreon, and } \\
\text { Stump, 2000). }\end{array}$ \\
\hline Repetition & $\begin{array}{l}\text { Words, phrases, stories, and } \\
\text { behaviors were often repeated } \\
\text { within moments of each other. } \\
\text { While this may be common } \\
\text { behavior for individuals with } \\
\text { Alzheimer's disease or dementia, } \\
\text { and was seen throughout the } \\
\text { entire day, it should be noted that } \\
\text { as the day passed, fatigue set in, } \\
\text { and participants became more } \\
\text { irritable, repetitive behaviors } \\
\text { became more frequent. }\end{array}$ & $\begin{array}{l}\text { The participant may be repeating } \\
\text { themselves because they are } \\
\text { struggling to make sense of what } \\
\text { is going on around them, feel } \\
\text { anxious, are comfort seeking, and } \\
\text { want reassurance (Regier, } \\
\text { Hodgson, and Gitlin, 2016). } \\
\text { When repetitive behaviors } \\
\text { increased, participants were } \\
\text { disengaged from activities and } \\
\text { rather solely focusing on and } \\
\text { seeking answers to their } \\
\text { questions. }\end{array}$ \\
\hline $\begin{array}{l}\text { Mood } \\
\text { disturbances }\end{array}$ & $\begin{array}{l}\text { Participants demonstrated } \\
\text { lingering moments of decreased } \\
\text { interest, energy and motivation; } \\
\text { often leading to agitated, }\end{array}$ & $\begin{array}{l}\text { Research has shown that time of } \\
\text { day (i.e. late afternoon and } \\
\text { evening) negatively affect the } \\
\text { mood of individuals with }\end{array}$ \\
\hline
\end{tabular}









\section{Glenner Town Square staff surveys: Participant behaviors which impact activity} engagement, activity and social participation, and supports and barriers to participation. The Glenner Town Square staff are participant assistants who lead group activities, provide meals, and assist with bathroom related needs of the Alzheimer's disease and dementia participants. The participant assistants detailed their daily interactions with the participants at Glenner Town Square through survey responses, explaining the behaviors they see which impact engagement in activities, their strategies for increasing activity and social participation amongst participants and the supports and barriers they experience. A copy of the survey questions can be found in Appendix B. An overview of the common themes identified from the surveys can be found below. Quotes have been derived from the written survey responses.

Theme 1: Current strategies to promote engagement. The Glenner Town square staff (i.e. participant assistants) identified several different strategies they use for redirecting a participant and getting them to engage or reengage in an activity. The responses from the Glenner Town Square staff survey can be found below in Table 2. The staff further expressed the desire for continued education on the Alzheimer's disease and dementia population. It may also be beneficial to incorporate how to adapt or modify an activity to meet the varying needs and abilities of the participants at Glenner Town Square, in order to increase activity engagement.

Table 2

Glenner Town Square Staff Survey Theme 1 Responses

\begin{tabular}{l|l} 
Theme & Responses \\
\hline
\end{tabular}




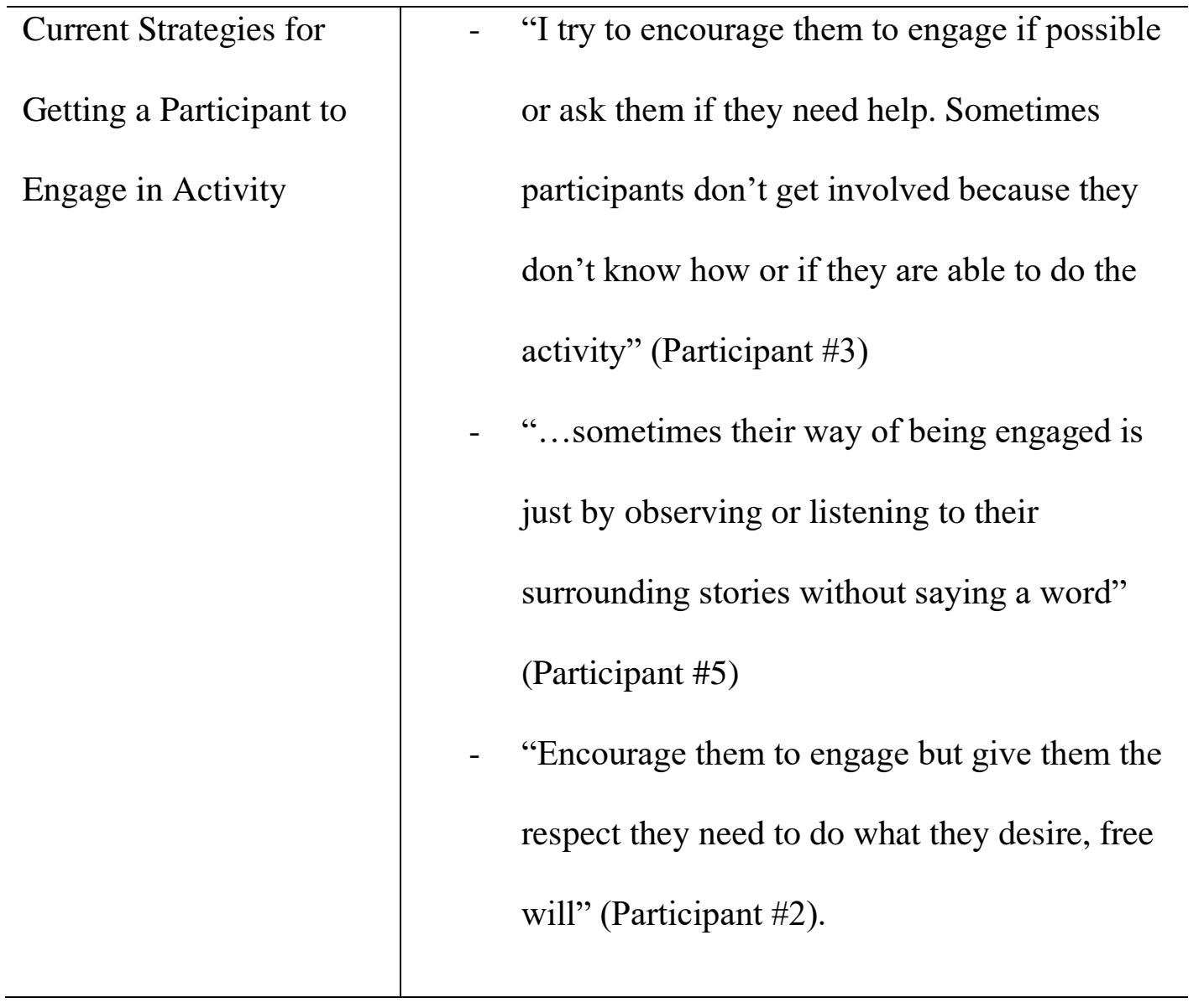

Theme 2: Strategies for increasing socialization between participants. The participant assistants further identified the current strategies they are using to increase social participation amongst participants. Social participation can be described as "The interweaving of occupations to support desired engagement in community and family activities as well as those involving peers and friends (Gillen and Boyt Schell, 2014, p.607). The participant assistants stated common strategies they used; as noted in their responses found below in table 3 .

Table 3

Glenner Town Square Staff Survey Theme 2 Responses

Theme
Responses 
ENHANCING ENGAGEMENT IN OLDER ADULTS WITH ALZHEIMER'S 26

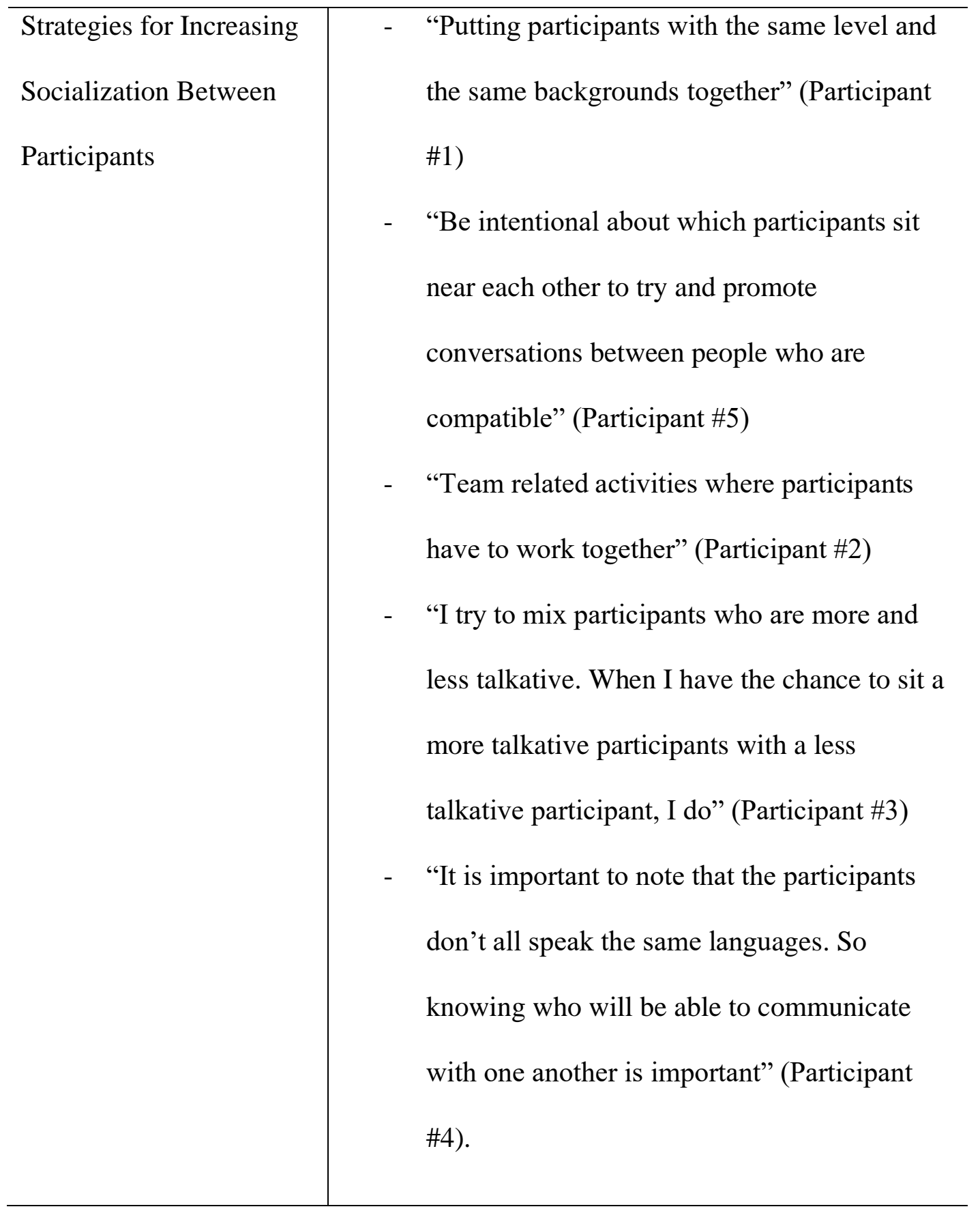

Theme 3: Barriers to participation in activities. The participant assistants also identified barriers to participation in activities for the participants at Glenner Town Square. Intrapersonal barriers such as personal feelings, and beliefs of self-ability, interpersonal barriers like communication between individuals, and structural constraints which consist of barriers outside 
the control of the individual were identified by the survey participants. Responses from the Glenner Town Square staff survey can be found below in table 4. Quotes have been derived from electronically recorded written survey responses.

Table 4

Glenner Town Square Staff Survey Theme 3 Responses

\begin{tabular}{|c|c|}
\hline Theme & Responses \\
\hline $\begin{array}{l}\text { Barriers to Participation } \\
\text { in Activities }\end{array}$ & $\begin{array}{l}\text { - "Wanting to go home after lunch and for the } \\
\text { rest of the day. Not wanting to go into totally } \\
\text { enclosed storefronts, but rather staying in the } \\
\text { more open spaces, like the park" (Participant } \\
\text { \#3) } \\
\text {-...increases in anxiety leads to exit seeking } \\
\text { behaviors, which causes a more disrespectful } \\
\text { attitude and sometimes they become more } \\
\text { aggressive" (Participant \#5) } \\
\text { “...some participants have inappropriate } \\
\text { behaviors. It can then make other participants } \\
\text { mad or irritated, causing conflict and } \\
\text { increased agitation among the group" } \\
\text { (Participant \#4). }\end{array}$ \\
\hline
\end{tabular}


Caregiver semi-structured group interviews. Caregivers of individuals with Alzheimer's disease or dementia expressed their ongoing experiences to be challenging, exhausting and overwhelming, due to the excessive amount of time and effort it takes to manage the disease. Concerns of financial burden, respite care, and managing personal health were also expressed. The caregiver's responses can be found below in table 5. An example of the questions asked during this semi-structured group interview can be found in Appendix C. Quotes have been derived from recorded group interviews and written question responses.

Table 5

Glenner Town Square Caregiver Group1 Semi-Structured Interview Responses

\begin{tabular}{|c|c|}
\hline Theme & Responses \\
\hline $\begin{array}{l}\text { Ongoing Experiences } \\
\text { Caring for an Individual } \\
\text { with Alzheimer's Disease } \\
\text { or Dementia }\end{array}$ & $\begin{array}{l}\text { - “... Caregiving is a full-time job, twenty-four } \\
\text { hours a day. It can be difficult to find alone } \\
\text { time or get a rest break. Not to mention the } \\
\text { financial strain" (Participant \# 4) } \\
\text { - "How am I going to continue to pay for } \\
\text { everything? The money is depleting quickly" } \\
\text { (Participant \#11) } \\
\text { "...Patience, patience, patience! Repeating } \\
\text { myself and constantly answering questions } \\
\text { over and over again can be exhausting. His } \\
\text { forgetfulness is exhausting" (Participant \#8) }\end{array}$ \\
\hline
\end{tabular}




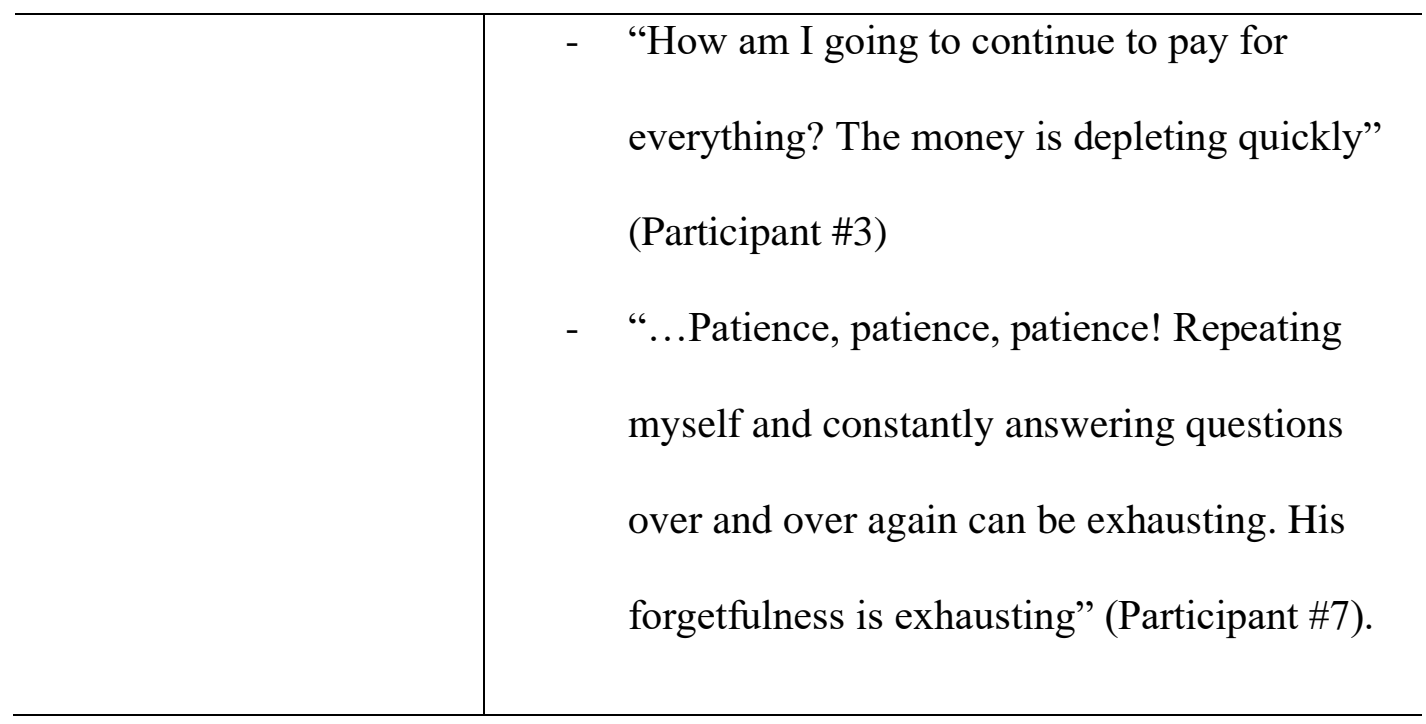

\section{Glenner Town Square Activity Recommendations}

Glenner Town Square has a wide variety (100+) activities for their participants to engage in over the course of a day, week, month, or even a year. For the purpose of this project, activity recommendations were made to the existing Glenner Town Square activities in order to maximize the more immediate and practical application of activity adaptations. The recommendations were made based on the literature review, participant observations, staff surveys, and the caregiver group semi-structured interviews. These current Glenner Town Square activity recommendations can be found below:

Exercise as an occupation. Provide more opportunities for the participants to engage in a variety of different exercises, such as playing games in the park or dancing. Exercise is an occupation that has the potential to reduce anxiety, agitation and restlessness for individuals with dementia (Stonerock, Hoffman, Smith, \& Blumenthal, 2015). 
Activity Examples: Corn-hole, golf, dancing, balloon volleyball, chair stretching, yoga, etc. See Appendix D for an example of how to adapt a dance exercise activity (i.e. "Senior Sit and Dance") to enhance activity engagement amongst participants at different cognitive levels.

Visual, auditory, and kinesthetic learners. Include visual, tactile, and verbal instructions (i.e. PowerPoint, pictures, handheld items, and verbal and written instruction, etc.) during all activities to increase participation amongst individuals who communicate and understand differently (i.e. theater reader activities, newsstand or T-bird "story time" activities). An example of these cueing techniques for the Theater Reader activity, along with the Goldilocks and the Three Bears PowerPoint incorporating the visual learning style can be located in Appendix E.

Cueing for increased activity engagement. During activities encourage staff to engage participants using cueing strategies that work best for the individual in order to spark spontaneous reminiscing and increase engagement. For example, determine if the participant requires a one-step verbal cue, tactile cueing in addition to the verbal cues, or if they can follow multi-step commands. Processing complex verbiage can be difficult to understand for individuals with Alzheimer's disease or dementia (American Occupational Therapy Association, 2017). See Appendix $\mathrm{F}$ for a list of potential cueing techniques that can be used during activities to increase participant engagement or spark spontaneous reminiscing.

Stimulating the senses. Incorporate more activities which focus on the participant's senses. Using the senses during an activity can help stimulate memories and past experiences (Amieva \& Dartigues, 2013). For example, placing various scents in different containers and having the participants smell and reminisce on past memories the participants experienced (i.e. 
vanilla $=$ baking, coffee $=$ morning). See Appendix $G$ for an example of how to facilitate this activity and a list of the required materials.

Partner or small group activities. Provide activity opportunities for participants to work together in partners or small groups of two or three rather than larger groups of five or more, in order to increase social participation amongst peers or fellow participants. Small group activities, designed to stimulate cognition for individuals with dementia, have shown to increase communication and social interaction amongst the population (Cohen-Mansfield, 2018). Partner work or small group activities, which focus on gross motor tasks, may also be relevant to addressing the effects of Sundowning. Partner or small group activity examples can be found in Appendix $\mathrm{H}$.

Schedule and activity routines. Reinforce schedule and activity routines at the start of each activity, or at the start of the day. Disorientation is common for individuals living with various forms of dementia and can be confusing. Research shows that individuals with dementia require structure and order in their environments to maintain orientation, and enhancing the environment to support the cognitive level of the individual is useful in those experiencing cognitive decline (i.e. written labels, written schedules and procedures, a visible calendar, bright colors, organized spaces (Nikander, 2009). An example of how to incorporate this activity can be found in Appendix I.

Table top activities to spark social participation. Incorporate small activities, pictures or items that could spark conversation between participants who sit in silence after meals, to increase social participation. Examples of table top social participation activities can be found in Appendix J. 
Easier transitions for the caregiver. Advise caregivers to take a picture of the participant in town square or of the participant with the staff at town square, and use it when their loved one is reluctant to come to town square and difficulties transitioning arises.

"Take Home Reports" for the caregiver. Provide a 'Take Home Report' of the activities participants participated in while at Town Square. Caregivers of the participants at Town Square reported difficultly communicating with their loved one at the end of their day, because their loved one does not remember what they participated in. The "Take Home Report" would facilitate an opportunity for communication between caregivers and their loved one. An example of how to incorporate the caregiver 'Take Home Report' can be found in Appendix K.

Ongoing opportunities for education. Provide ongoing training to staff on working with individuals with Alzheimer's disease and dementia. While they may have a good foundation of understanding, ongoing training and refreshers can help staff to stay relevant and up to date on providing the best care for this population. For example, reminding staff that doing an activity with a participant can be much more effective than doing an activity for the participant. An example of available resources for ongoing education can be found in Appendix L.

\section{Chapter V. Summary, Discussion and Conclusion}

\section{Summary}

The objectives of this capstone project were to complete a needs assessment identifying the activity engagement and social participation needs of individuals with Alzheimer's disease and dementia at an adult day care reminiscence therapy program, and then propose program recommendations to the staff on adapting current activities to meet the identified population needs. Identified behaviors from the observation of the Alzheimer's disease and dementia 
population at Glenner Town Square was connected to decreased activity engagement and social participation. Current staff discussed their experiences with lack of participation, disengagement, and the ongoing barriers to redirect or reengage participants in activities. Caregivers expressed their day to day concerns and challenges living with and caring for an individual with Alzheimer's disease or dementia. The needs assessment ultimately supported the limited research currently available on the role occupational therapy and reminiscence therapy play on activity engagement, social participation and occupational performance in individuals with Alzheimer's disease and dementia.

\section{Discussion}

Participant observation, staff survey and caregiver semi-structured interviews support previous research that individuals with Alzheimer's disease and dementia experience difficulties related to memory, thinking, orientation, perception, and behavior, which ultimately impacts

their ability to fully participate in everyday activities (Herke et. al, 2018). The unpredictability of Alzheimer's disease and dementia can impact an individual physically, socially, and emotionally; resulting in decreased social participation and occupational performance (Cerejeira, Lagarto, \& Mukaetova-Ladinska, 2012). Occupational therapy has an expert understanding of the relationship between an individual, the environment, and the occupational activity which is required for successful activity participation (Manni, Federzoni, Garzetta, Graff \& Fabbo, 2018). The role of occupational therapy in the reminiscence therapy environment for individuals with Alzheimer's disease and dementia is to determine the best fit, or the "just-right-challenge" between the environment and task demands, and the cognitive ability of the participant (Manni, et. al, 2018). The aim of this project was to complete a needs assessment at Glenner Town Square, an adult day reminiscence therapy facility for individuals with Alzheimer's disease and 
dementia; and then develop program recommendations for current activities, which focus on memory, cognition, activity engagement, social participation, and overall occupational performance.

\section{Limitations and Barriers}

Limitations came to the forefront through the ongoing course of this capstone experience project. The first limitation of this project was the time constraints and availability of caregivers to be interviewed or complete a survey. For most caregivers, the only respite care they have available is when their loved one is at Glenner Town Square. Respite care is defined as shortterm relief for primary caregivers (Roberts \& Struckmeyer, 2018). Caregivers of participants at Glenner Town Square expressed reluctance to find extra time to participate in an in person or virtual interview or take a survey. This limited the volume and ability to conduct in depth interviews with the caregivers. Instead, a short, group semi-structured interview was conducted.

The second limitation of this project was the number of respondents to the staff survey. The survey was sent out to all Glenner Town Square staff, approximately 20 to 30 people, yet only 5 people responded. This could be due to the high demand it takes to provide care to individuals with Alzheimer's disease or dementia, and the willingness to respond to a voluntary survey. The staff responses varied in length and complexity, and some gave a more simplistic answer to the question, and because it was in survey form, this limited the ability for follow up questions. A longer study may have provided more time and opportunity for more staff to respond to the survey.

Lastly, the project focus on only adapting current activates at Glenner Town Square limited the ability to evolve this project into the program development phase of new activities with a more occupation-based focus. The initial focus on adapting the facilities current activities 
was chosen in order to make these activity adaptations easier for Glenner Town Square to effectively implement into their daily activity programming; in order to increase activity engagement and social participation. However, this focus on current activities became a limitation to the expansiveness of the activity recommendations and a barrier to the development of new occupational-based activities which could have been created; ultimately impacting the overall outcome of the project.

\section{Implications for Occupational Therapy}

As previously mentioned, The American Occupational Therapy Association's vision for 2025 is to "maximize health, well-being, and quality of life for all people, populations, and communities through effective solutions that facilitate participation in everyday living" (American Occupational Therapy Association, 2016, para. 1). This capstone experience project highlights how occupational therapy and reminiscence therapy can benefit the Alzheimer's disease and dementia population, and how it can support practitioners in the ongoing use of the two together.

The results of this capstone experience may have the following implications for occupational therapy practice:

- Occupational therapists have a unique specialty in understanding and adapting or modifying an individual's environment and matching it to the task demands, as it relates to the cognitive ability of the individual within the constructs of their Alzheimer's disease and dementia.

- Opportunities for occupational therapists to work within the reminiscence therapy environment by using the activity engagement and social participation recommendations to further develop and implement occupation-based activities or 
programs, has the potential to benefit the occupational performance and social participation of the Alzheimer's disease and dementia population.

- Occupational therapy barriers to serving the Alzheimer's disease and dementia population include limited research as it relates to reminiscence therapy, decreased access to patient and caregivers due to time constraints, and a limited understanding of the role of occupational therapy with this population.

\section{Future Research and Program Development}

Based on the results of this capstone experience project, there is a clear argument for the use of occupational therapy and reminiscence therapy with the Alzheimer's disease or dementia population as it relates to increased activity engagement and social participation, and overall occupational performance. Future studies should continue to identify the ongoing needs of this population at Glenner Town Square and review how implementing the suggested activity engagement and social participation recommendations into the current activity design and program development conclude. A study reviewing how the implementation of these recommendations impact the social participation and activity engagement of the participants at Glenner Town Square could be completed in order to better understand how the proposed recommendations impact the Alzheimer's disease and dementia population.

Routine actions or tasks which have been mastered in the past are more easily retained as a procedural memory by individuals with dementia (Nakamae, Yotsumoto, Tatsumi, and Hashimoto, 2014). Developing and implementing new programming which focuses on occupation-based, task-oriented, procedural memory activities which are connected to the participants interests and pasts, would be beneficial to effectively combining occupational therapy with reminiscence, as it relates to the Alzheimer's disease and dementia population. An 
example of this type of activity could include a meaningful cooking activity, or a homemaking activity (i.e. quilting or sewing). To take the study further, a review of how the population's activity engagement and social participation was impacted by these activities could be analyzed.

Lastly, the initially proposed Glenner Town Square current activity recommendations could also be used to design and develop an educational program for Glenner Town Square staff and their Alzheimer's disease and dementia population. A study by Surr, Gates, Irving, Oyebode, and Smith (2017), explores the current dementia-care workforce, related to knowledge, continuing education, and ability to provide effective care for individuals with Alzheimer's disease and dementia. Developing a program which addresses the identified concerns could be beneficial to positively impacting the occupational performance, social participation and activity engagement of the Glenner Town Square participants.

\section{Conclusion}

Alzheimer's disease is a neurodegenerative form of dementia, which causes individuals to gradually lose their ability to live and function independently (Isaacson, 2019). By promoting positive feelings through the review of their life experiences, reminiscence therapy has shown to have positive effects on the mental health, cognitive, and social skills in older adults with Alzheimer's disease and dementia (Shropshire, 2020). Occupational therapy has the potential to support individuals with Alzheimer's disease or dementia in order to maintain cognitive function, achieve meaningful goals, regulate self-management, and modify activities which help reduce behavioral symptoms and functional dependence (Field, Coates \& Mountain, 2018). However, reminiscence therapy and occupational therapy are not currently working together in the treatment or maintenance of the Alzheimer's disease and dementia population. This capstone experience project has identified the activity engagement and social participation needs of the 
Alzheimer's disease and dementia population at Glenner Town Square and made recommendations on their current activities; focusing on memory, cognition, activity engagement, and social participation through the use of occupational therapy. These recommendations support previous research on the potential for occupational therapy and reminiscence therapy to improve the occupational performance of individuals with Alzheimer's disease and dementia. 


\section{References}

Allen, C. K. (1992). Cognitive disabilities. In N. Katz (Ed.), Cognitive rehabilitation: Models for intervention in occupational therapy (pp. 1-21). Stoneham, MA: Butterworth-Heinemann.

Alz.org (2014). Utah's state plan for Alzheimer's disease and related dementias action plan for 20122017. Retrieved from http://www.alz.org/national/documents/utah_stateplan_2012.pdf

Alzate, L. (2018). Alzheimer's disease. Nutritional Perspectives: Journal of the Council on Nutrition, 41(2), 28-35.

American Occupational Therapy Association. (2011). Alzheimer's disease tip sheet. Retrieved from https://www.aota.org/About-Occupational-Therapy/Patients-Clients/Adults/Alzheimers.aspx American Occupational Therapy Association. (2016). AOTA unveils Vision 2025. Retrieved from https://www.aota.org/AboutAOTA/vision-2025.aspx

American Occupational Therapy Association. (2017). Occupational therapy practice guidelines for adults with Alzheimer's disease and related major neurocognitive disorders. Retrieved from https://myaota.aota.org/shop aota/product/900408U

Amieva, H., \& Dartigues, J.-F. (2013). ETNA3, A clinical randomized study assessing three cognitive-oriented therapies in dementia: Rationale and general design. Revue Neurologique, 169(10), 752-756. https://doi.org/10.1016/j.neurol.2013.07.011

Ayyalasomayajula, N., \& Suresh, C. (2018). Mechanistic comparison of current pharmacological treatments and novel phytochemicals to target amyloid peptides in Alzheimer's and neurodegenerative diseases. Nutritional Neuroscience, 21(10), 682-694. https://doi.org/10.1080/1028415X.2017.1345425

Baum, C. M. (2011). The contribution of occupation to function in persons with Alzheimer's disease. Journal of Occupational Science, 2(2), 59-67. https://doi.org/10.1080/14427591.1995.9686396 
ENHANCING ENGAGEMENT IN OLDER ADULTS WITH ALZHEIMER'S 40

Blake, M. (2013). Group reminiscence therapy for adults with dementia: A review. British Journal of Community Nursing, 18(5), 228-233. https://doi.org/10.12968/bjcn.2013.18.5.228

Boyden, D. E., Miltenberger, R. G., \& Novotny, M. A. (2020). Evaluating the influence of time of day on activity engagement in persons with dementia. Behavioral Interventions, 35(1), 156-165. https://doi.org/10.1002/bin.1697

Cerejeira, J., Lagarto, L., \& Mukaetova-Ladinska, E. B. (2012). Behavioral and psychological symptoms of dementia. Frontiers in Neurology, 3. https://doi.org/10.3389/fneur.2012.00073

Christie, A. (1999). A meaningful occupation: The just right challenge. Australian Occupational Therapy Journal, 46(2), 52-68. https://doi.org/10.1046/j.1440-1630.1999.00178.x

Cohen-Mansfield, J. (2018). The impact of group activities and their content on persons with dementia attending them. Alzheimer's Research \& Therapy, 10. https://doi.org/10.1186/s13195$\underline{018-0357-\mathrm{Z}}$

Corvol, A., Netter, A., Campeon, A., \& Somme, D. (2018). Implementation of an occupational therapy program for Alzheimer's disease patients in France: Patients' and caregivers' perspectives. Journal of Alzheimer's Disease, 62(1), 157-164. https://doi.org/10.3233/JAD170765

Cotelli, M., Manenti, R., \& Zanetti, O. (2012). Reminiscence therapy in dementia: A review. Maturitas, 72(3), 203-205. https://doi.org/10.1016/j.maturitas.2012.04.008

Day, K., Carreon, D., \& Stump, C. (2000). The therapeutic Design of environments for people with dementia: A review of the empirical research. The Gerontologist, 40(4), 397-416. https://doi.org/10.1093/geront/40.4.397 
Edwards, M. (2015). Family caregivers for people with dementia and the role of occupational therapy.

Physical \& Occupational Therapy in Geriatrics, 33(3), 220-232.

https://doi.org/10.3109/02703181.2015.1031926

Elfil, M., \& Negida, A. (2017). Sampling methods in clinical research: An educational review. Emergency, 5(1), e52. https://www.ncbi.nlm.nih.gov/pmc/articles/PMC5325924/

Engelman, K., Altus, D. \& Mathews, R. (2013). Increasing engagement in daily activities by older adults with dementia. Journal of Applied Behavior Analysis, 32(1), 107-110. https://doi.org/10.1901/jaba.1999.32-107

Field, B., Coates, E., \& Mountain, G. (2018). Influences on uptake of a community occupational therapy intervention for people with dementia and their family carers: British Journal of Occupational Therapy. https://doi.org/10.1177/0308022618804479

Fletcher, T. S., \& Eckberg, J. D. (2014). The effects of creative reminiscing on individuals with dementia and their caregivers: A pilot study. Physical \& Occupational Therapy in Geriatrics, 32(1), 68-84. https://doi.org/10.3109/02703181.2014.880863

Gillen, G., \& Boyt Schell, B. (2014). Introduction to evaluation, intervention, and outcomes for occupations. In B. A. Boyt Schell, G. Gillen, \& M. Scaffa (Eds.), Willard and Spackman's occupational therapy (12th ed., pp. 606-609). Philadelphia: Lippincott Williams \& Wilkins.

Hall, C. (2018). Learning styles and the ot patient-OT Toolkit ${ }^{T M}$. Retrieved from https://www.ottoolkit.com/blog/learning-styles-and-the-ot-patient/

Herke, M., Fink, A., Langer, G., Wustmann, T., Watzke, S., Hanff, A., \& Burckhardt, M. (2018). Environmental and behavioural modifications for improving food and fluid intake in people with dementia. The Cochrane Database of Systematic Reviews, 2018(7).

https://doi.org/10.1002/14651858.CD011542.pub2 
Huang, H.-C., Chen, Y.-T., Chen, P.-Y., Huey-Lan Hu, S., Liu, F., Kuo, Y.-L., \& Chiu, H.-Y. (2015). Reminiscence therapy improves cognitive functions and reduces depressive symptoms in elderly people with dementia: A meta-analysis of randomized controlled trials. Journal of the American Medical Directors Association, 16(12), 1087-1094. https://doi.org/10.1016/j.jamda.2015.07.010

Hwang, J.-L. E., Rivas, J. G., Fremming, R., Rivas, M. M., \& Crane, K. R. (2009). Relationship between perceived burden of caring for a family member with Alzheimer's disease and decreased participation in meaningful activities. Occupational Therapy in Health Care, 23(4), 249-266. https://doi.org/10.3109/07380570903214788

Isaacson, R. S. (2019). Advances in early diagnosis and treatment strategies in the management of Alzheimer's disease. Journal of Managed Care Medicine, 22(4), 17-21. http://jmcmpub.org/wpcontent/uploads/2019/10/22.4_ship_hires.pdf\#page $=17$

Kawulich, B. B. (2005). Participant observation as a data collection method. Forum Qualitative Sozialforschung / Forum: Qualitative Social Research, 6(2). https://doi.org/10.17169/fqs-6.2.466

Lanzoni, A., Fabbo, A., Basso, D., Pedrazzini, P., Bortolomiol, E., Jones, M., \& Cauli, O. (2018). Interventions aimed to increase independence and well-being in patients with Alzheimer's disease: Review of some interventions in the Italian context. Neurology, Psychiatry and Brain Research, 30, 137-143. https://doi.org/10.1016/j.npbr.2018.10.002

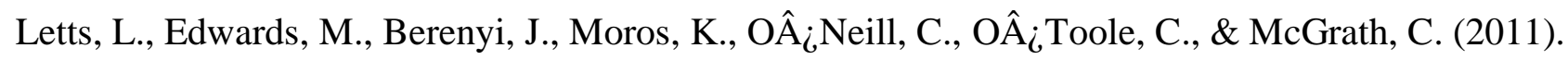
Using occupations to improve quality of life, health and wellness, and client and caregiver satisfaction for people with Alzheimer's disease and related dementias. American Journal of Occupational Therapy, 65(5), 497-504. https://doi.org/10.5014/ajot.2011.002584 
Lök, N., Bademli, K., \& Selçuk-Tosun, A. (2018). The effect of reminiscence therapy on cognitive functions, depression, and quality of life in Alzheimer patients: Randomized controlled trial. International Journal of Geriatric Psychiatry, 34(1), 47-53. https://doi.org/10.1002/gps.4980

MacKenzie, D. E., \& Westwood, D. A. (2013). Occupational therapists and observation: What are you looking at? OTJR: Occupation, Participation and Health, 33(1), 4-11. https://doi.org/10.3928/15394492-20120928-01

Manni, B., Federzoni, L., Lanzoni, A., Garzetta, G., Graff, M., \& Fabbo, A. (2018). Occupational therapy in special respite care: A new multicomponent model for challenging behavior in people with dementia. Geriatric Care, 4(3), Article 3. https://doi.org/10.4081/gc.2018.7649

Melendez, J. C., Torres, M., Redondo, R., Mayordomo, T., \& Sales, A. (2017). Effectiveness of follow-up reminiscence therapy on autobiographical memory in pathological ageing. International Journal of Psychology, 52(4), 283-290. https://doi.org/10.1002/ijop.12217

Nakamae, T., Yotsumoto, K., Tatsumi, E., \& Hashimoto, T. (2014). Effects of productive activities with reminiscence in occupational therapy for people with dementia: A pilot randomized controlled study. Hong Kong Journal of Occupational Therapy, 24(1), 13-19. https://doi.org/10.1016/j.hkjot.2014.01.003

Nazarko, L. (2011). Tackling “sundowning” in dementia care. British Journal of Healthcare Assistants, 5(11), 544-547.https://doi.org/10.12968/bjha.2011.5.11.544

Newcomer, Kathryn E. (2015), Handbook of practical program evaluation, John Wiley \& Sons, Incorporated,. ProQuest Ebook Central, http://ebookcentral.proquest.com/lib/umanitoba/detail.action?docID=2144898

Padilla, R. (2011). Effectiveness of interventions designed to modify the activity demands of the occupations of self-care and leisure for people with Alzheimer's disease and related dementias. 
American Journal of Occupational Therapy, 65(5), 523-531.

https://doi.org/10.5014/ajot.2011.002618

Pedroso, R. V., Ayán, C., Fraga, F. J., da Silva, T. M. V., Cancela, J. M., \& Santos-Galduròz, R. F. (2018). Effects of functional-task training on older adults with Alzheimer's disease. Journal of Aging \& Physical Activity, 26(1), 97-105. doi: 10.1123/japa.2016-0147

Ponto, J. (2015). Understanding and Evaluating Survey Research. Journal of the Advanced Practitioner in Oncology, 6(2), 168. PMCID: PMC4601897

Raggi, A., Tasca, D., Panerai, S., Neri, W., \& Ferri, R. (2015). The burden of distress and related coping processes in family caregivers of patients with Alzheimer's disease living in the community. Journal of the Neurological Sciences, 358(1), 77-81.

https://doi.org/10.1016/j.jns.2015.08.024

Rathbone, C. J., Ellis, J. A., Ahmed, S., Moulin, C. J. A., Ernst, A., \& Butler, C. R. (2019). Using memories to support the self in Alzheimer's disease. Cortex. 121, 332-346. https://doi.org/10.1016/j.cortex.2019.09.007

Regier, N. G., Hodgson, N. A., \& Gitlin, L. N. (2016). Characteristics of activities for persons with dementia at the mild, moderate, and severe stages. The Gerontologist, gnw133. https://doi.org/10.1093/geront/gnw133

Roberts, E., Struckmeyer, K. M., (2018). The impact of respite programming on caregiver resilience in dementia care. Inquiry: A Journal of Medical Care Organization, Provision and Financing, 55. https://doi.org/10.1177/0046958017751507

Santos da Silva, M. I., de Oliveira Alves, A. N., Barros Leite Salgueiro, C. D., \& Bezerra Barbosa, V. F. (2018). Alzheimer's disease: Biopsychosocial repercussions in the life of the family caregiver. 
Journal of Nursing UFPE / Revista de Enfermagem UFPE, 12(7), 1931-1939.

https://doi.org/10.5205/1981-8963-v12i7a231720p1931-1939-2018

Smallfield, S., \& Heckenlaible, C. (2017). Effectiveness of occupational therapy interventions to enhance occupational performance for adults with Alzheimer's disease and related major neurocognitive disorders: A systematic review. American Journal of Occupational Therapy, 71(5), 7105180010p1-7105180010p9. https://doi.org/10.5014/ajot.2017.024752

Shropshire, M. (2020). Reminiscence intervention for community-dwelling older adults without dementia: A literature review. British Journal of Community Nursing, 25(1), 40-44.

Stonerock, G. L., Hoffman, B. M., Smith, P. J., \& Blumenthal, J. A. (2015). Exercise as treatment for anxiety: systematic review and analysis. Annals of Behavioral Medicine : A Publication of the Society of Behavioral Medicine, 49(4), 542-556. https://doi.org/10.1007/s12160-014-9685-9

Surr, C. A., Gates, C., Irving, D., Oyebode, J., Smith, S. J., Parveen, S., Drury, M., \& Dennison, A. (2017). Effective dementia education and training for the health and social care workforce: a systematic review of the literature. Review of Educational Research, 87(5), 966-1002. https://doi.org/10.3102/0034654317723305

Swann, J. I. (2013). Dementia and reminiscence: Not just a focus on the past. Nursing \& Residential Care, 15(12), 790-795. https://doi.org/10.12968/nrec.2013.15.12.790

Teherani, A., Martimianakis, T., Stenfors-Hayes, T., Wadhwa, A., \& Varpio, L. (2015). Choosing a qualitative research approach. Journal of Graduate Medical Education, 7(4), 669-670. https://doi.org/10.4300/JGME-D-15-00414.1

Walker, B. A., Allen, J., Koch, M. A., Sprehe, C., \& Webber, K. T. (2017). Identifying effective strategies in occupational therapy to support persons with Alzheimer's disease and their 
ENHANCING ENGAGEMENT IN OLDER ADULTS WITH ALZHEIMER'S 46

caregivers. American Journal of Occupational Therapy, 71, 113-113.

https://doi.org/10.5014/ajot.2017.71S1-PO6036

Wang, H.-X., Xu, W., \& Pei, J.-J. (2012). Leisure activities, cognition and dementia. Biochimica et Biophysica Acta (BBA) - Molecular Basis of Disease, 1822(3), 482-491. https://doi.org/10.1016/j.bbadis.2011.09.002

Warchol, K. (2017). Middle stage dementia: Techniques to maximize function. https://www.crisisprevention.com/Blog/November-2010/Middle-Stage-Dementia-Techniques-to$\underline{\text { Maximize-Funct }}$

Winblad, B., Amouyel, P., Andrieu, S., Ballard, C., Brayne, C., Brodaty, H. Zetterberg, H. (2016). Defeating Alzheimer's disease and other dementias: A priority for European science and society. The Lancet Neurology; 15(5), 455-532. http://dx.doi.org.prx-usa.lirn.net/10.1016/S1474$\underline{4422(16) 00062-4}$

Woods, B., Aguirre, E., Spector, A. E., \& Orrell, M. (2012). Cognitive stimulation to improve cognitive functioning in people with dementia. Cochrane Database of Systematic Reviews, (2). https://doi.org/10.1002/14651858.CD005562.pub2

Yamagami, T., Oosawa, M., Ito, S., \& Yamaguchi, H. (2007). Effect of activity reminiscence therapy as brain-activating rehabilitation for elderly people with and without dementia. Psychogeriatrics, 7(2), 69-75. https://doi.org/10.1111/j.1479-8301.2007.00189.x 


\section{Appendix A}

Glenner Town Square List of Observed Activities

1. Floral Arrangements

2. Left, Right, Center

3. National Geographic - Pet Shop

4. Storytelling/Readers Theater

5. Trivia

6. Chair Yoga

7. Music Sing-Along

8. Titanic Tales Discussion

9. Cooking Activities/Dessert Design

10. Arts \& Crafts

11. Magazine Treasure Hunt

12. Show \& Tell

13. Air \& Space Discussion

14. Poker

15. Poetry

16. Aquarium Discussion

17. Puzzles

18. Bingo/Loteria

19. Sittercise

20. Movie of Choice 
21. Hotel Mysteries Discussion

22. 100 Interesting Facts

23. Table Games

24. Model Airplanes Discussion

25. OT Student Placemat Activities

26. "I Love Lucy" Shows

27. Jewelry Making

28. Water Colors

29. Postcards to the Troops

30. Planting and Seeding

31. Poetry

32. Pictionary

33. Parachute \& Lawn Games

34. Science Experiment

35. Book Club

36. Meals/Snacks

37. Inventory/Sorting 


\title{
Appendix B
}

\author{
Glenner Town Square Staff Survey Questions
}

1. What do you feel like the needs of the Alzheimer's disease and dementia population are?

2. What are some typical behaviors you see from participants? (Positive or Negative)

3. What strategies have you used to overcome the challenging behaviors? Did they work?

4. Do you see a difference in participation or changed behaviors based on the time of day?

5. What time of day is most challenging to get participants to engage?

6. What do you do when a participant is not engaging in an activity?

7. How do you promote spontaneous reminiscing with participants?

8. What do you do or what would you suggest to increase socialization between participants?

9. What barriers or supports do you see to participation (i.e. environmental, activity modification, etc.)?

10. Does participant memory/cognition improve or decline based on the task or activity they are engaged in?

11. Do you feel cultural background plays a role in the participation of activities?

12. Do you have task or activity suggestions you would like to see incorporated at Glenner Town Square to help participants engage? 
ENHANCING ENGAGEMENT IN OLDER ADULTS WITH ALZHEIMER'S 50

\section{Appendix C}

\section{Group Caregiver Semi-Structured Interview Questions}

1. What are the three greatest challenges or barriers you experience on a day to day basis caring for an individual with Alzheimer's disease or dementia?

2. What do you feel like are the daily needs or your loved one with Alzheimer's disease or dementia?

3. What are your needs as a caregiver to someone with Alzheimer's disease or dementia? 


\section{Appendix D}

\section{Exercise as an Occupation Activity}

*For the purpose of this project, this activity recommendation was made to an existing Glenner Town Square exercise activity in order to maximize the increases in social participation and activity engagement of their Alzheimer's disease and dementia population. This ultimately maximizes the more immediate and practical implementation of the activity adaptation recommendations into the Glenner Town Square programming.

"Senior Sit and Dance" is a way to adapt the current exercise regimen being implemented at Glenner Town Square, by mixing-up the type of exercise participants are getting on a day to day basis, with a focus on motivating them to get moving and stay more engaged in the activity. This has the ability to increase self-esteem, autonomy, mood, and mental abilities, while decreasing agitation, wandering or anxiety, using principles of stretch, balance, and cardio-dance movements (Alz.org, 2014). The occupation of dancing as a form of exercise, has the potential for increased social participation and reminiscence effects based on the selection of music, and its cultural relevance to the group. The teaching resource manual for the "Senior Sit and Dance" activity includes teaching guidelines for all ability levels, suggestions on how to keep participants motivated, safety precautions, the curriculum and exercises, music suggestions, and dance steps which can be purchased at seniorsitanddance.com for $\$ 49.95$.

Occupational therapists believe that engagement in occupations or meaningful activities should be met by the "just right challenge", by which the activity is neither too easy, nor too difficult for an individual (Christie, 2002). Activity adaptations or modifications should be especially noted for optimal activity participation. Below are a few ways to make the "Senior Sit 
and Dance" activity more difficult or a little easier depending on the level the participant it able to engage in.

For increased difficulty:

- Have the participant stand.

- Have the participant lead the group.

- Have the participant make up a dance for the group, and lead it.

For decreased difficulty:

- Have the participant remain seated.

- Provide hand-over-hand tactile cueing to help the participant complete the dance movements along with you.

- Position the participant in the front, near the person leading the group for increased visual cueing.






\section{Appendix E}

\section{Theater Reader Activity}

*For the purpose of this project, this activity recommendation was made to an existing Glenner Town Square activity in order to maximize the increases in social participation and activity engagement of their Alzheimer's disease and dementia population. This ultimately maximizes the more immediate and practical implementation of the activity adaptation recommendations into the Glenner Town Square programming.

Every individual learns in a unique way, and providing a variety of opportunities to keep participants engaged in an activity can be beneficial to their occupational participation. The Occupational Therapy Toolkit breaks down learning into three different styles, visual, auditory, and kinesthetic or physical (Hall, 2018). Incorporating visual aids such as illustrated handouts with step-by-step instructions, modeling the motions, providing short video clips along with the activity, or using colors to highlight important information can be beneficial for a visual learner (Hall, 2018). Auditory learners may benefit from describing things in their own words, having the activity explained to them out loud, playing music or recordings, having the individual read the material aloud, and then encouraging questions (Hall, 2018). Kinesthetic or physical learners learn by doing, and may benefit from doing the activity alongside others, visualizing or thinking about the activity before doing it, or communicating during an activity (Hall, 2018). Using tools such as a visual PowerPoint for the Theater Reader activity, along with the "acting" (kinesthetic or physical) or outload reading of the story (auditory), may be beneficial for participants to increase engagement in activities. 

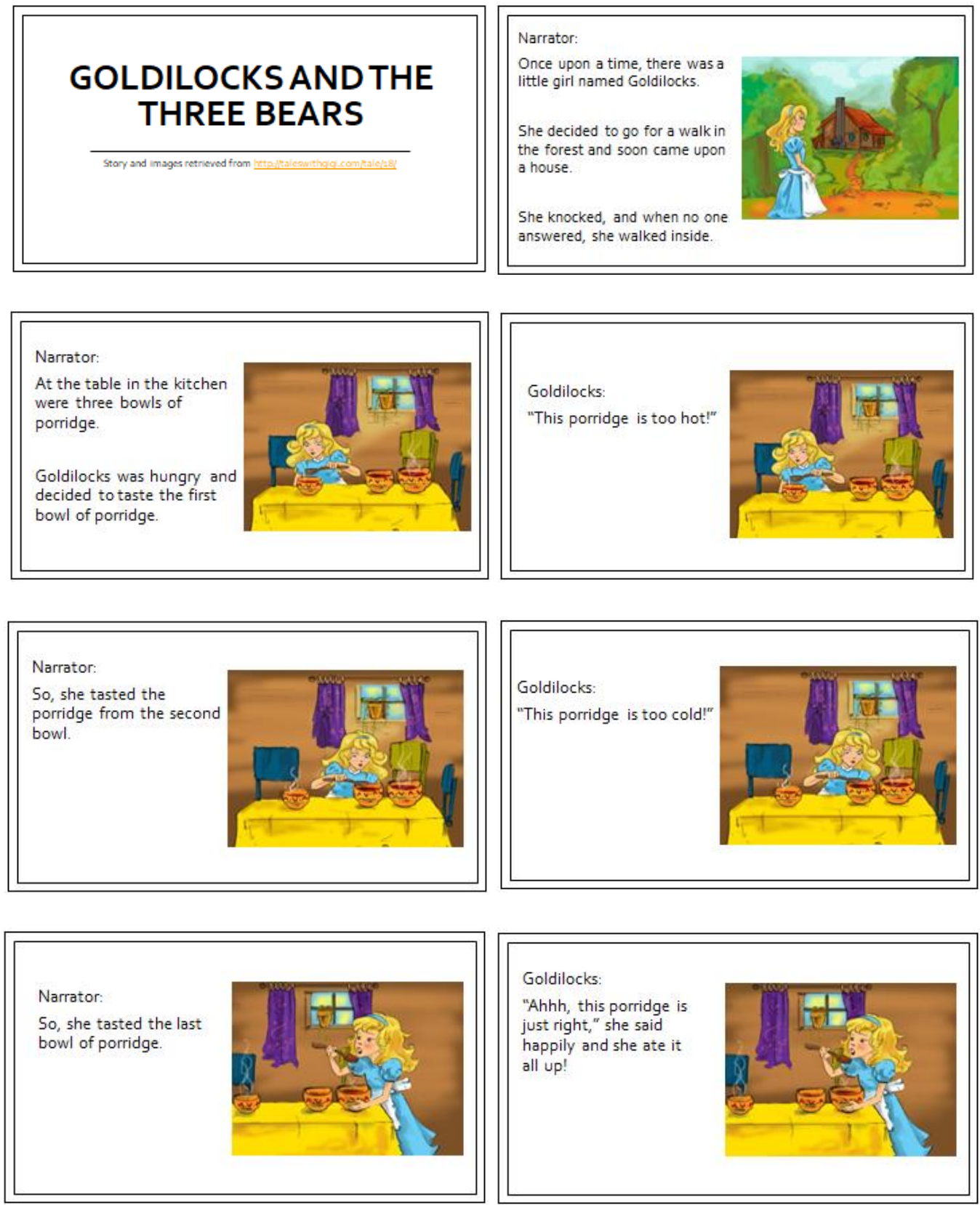
ENHANCING ENGAGEMENT IN OLDER ADULTS WITH ALZHEIMER'S 55
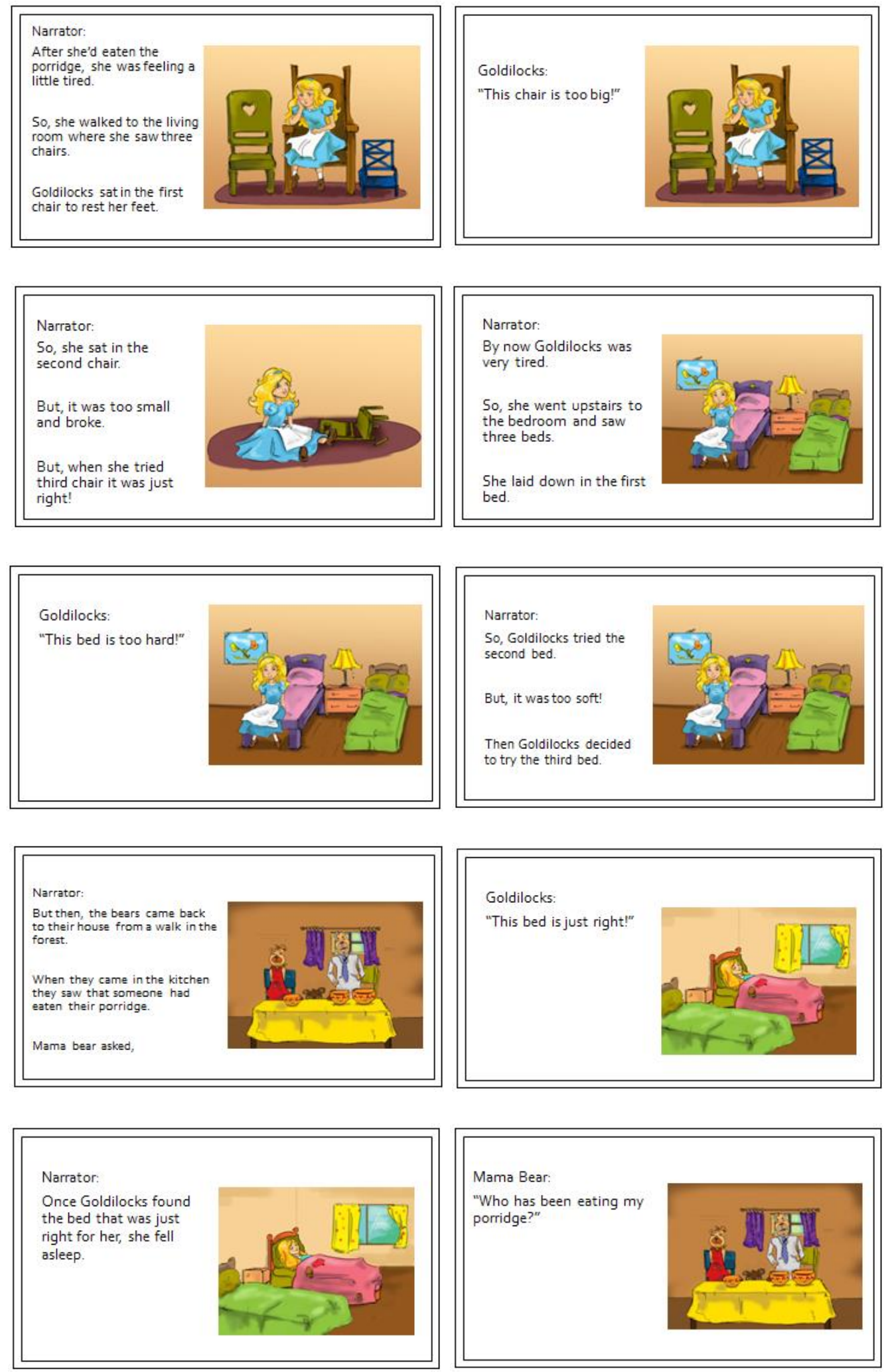
ENHANCING ENGAGEMENT IN OLDER ADULTS WITH ALZHEIMER'S 56
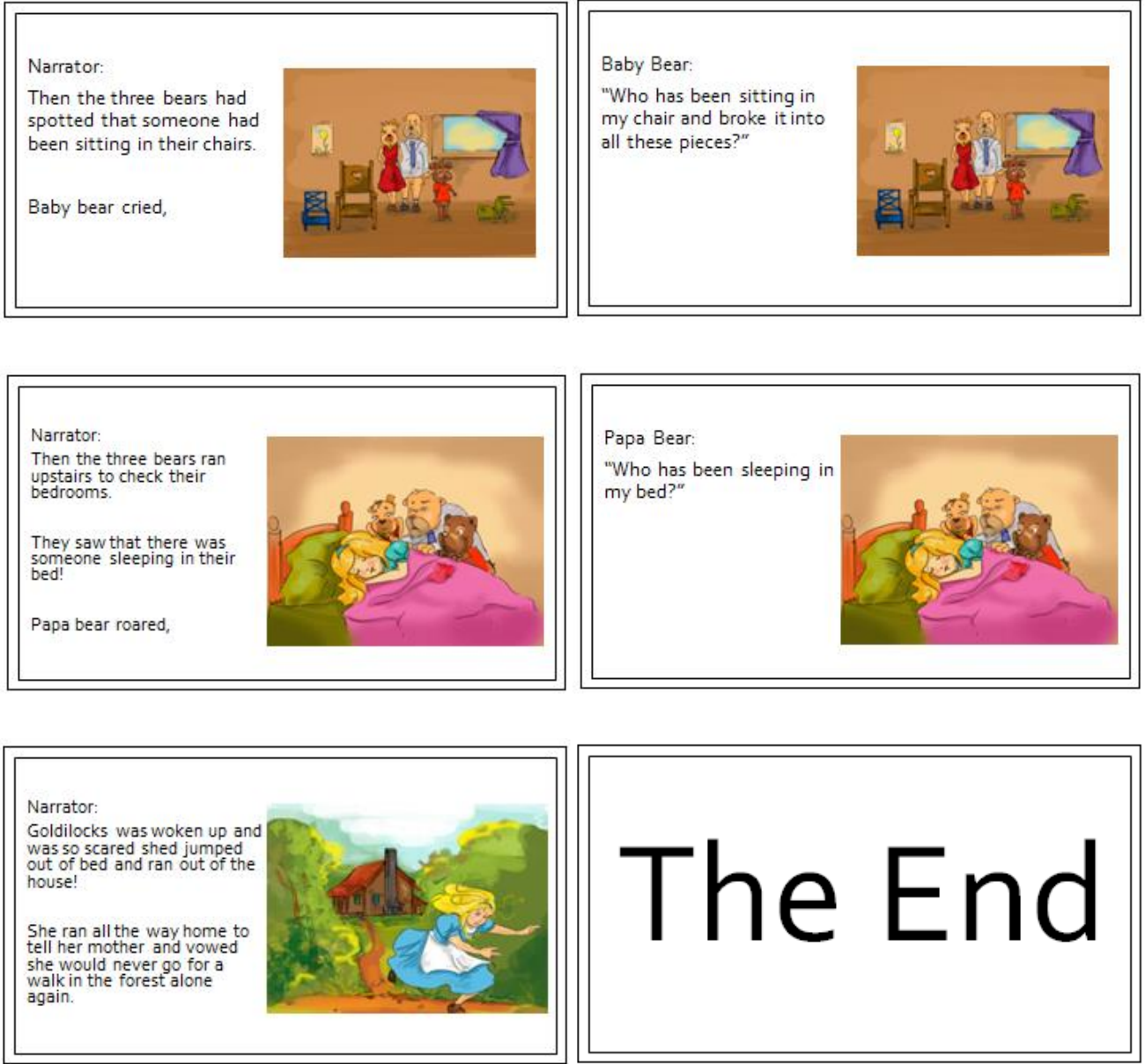


\author{
Appendix F \\ Cueing Techniques for Increased Activity Engagement
}

One-step verbal cueing: Breaking an activity down into one-step segments for an individual with dementia can be extremely important for increased engagement due to challenges with memory or recalling how to complete a task (Warchol, 2017).

- When transitioning to different activities, use phrases such as, "Jim, please sit down", “Jim please stand up", “Jim, please follow me", or "Jim, walk with me".

- When engaging in an activity such as magazine treasure hunt or a cooking activity, use phrases such as, "Jim, show me how to roll the dough.", "Jim, show me where the dog is.", “Jim, where have you traveled?", “Jim, what is your favorite food?", or “Jim, do you like to cook?".

Tactile cueing: 5-10 seconds after giving a verbal cue, with no response, engage the participant with a tactile or hands on cue, which can be more beneficial to facilitate engagement (Warchol, 2017). Tactile cues have the ability to reduce anxiety in an individual with dementia and may be the nudge they need to get over the hurdle keeping them from participating (Warchol, 2017).

- If the participant doesn't respond to the verbal cue when transitioning to different activities, use a tactile cue, such as placing your hand on their shoulder and saying "Jim, stand up" Or "Jim, come with me".

During a table top art activity, flower arrangement activity, or a poker activity, using a tactile cue such as placing your hand over the participant's hand and showing them what to do 
next can help the participant remain engaged or re-engage in the activity. (i.e. place your hand over the participants while they hold a paint brush, together dip the brush in the paint and make a stroke on the paper. Ask the participant to repeat or continue using the tactile cue to facilitate engagement). 


\section{Appendix G}

\section{Stimulating the Senses Activity}

Create "scent bottles" by placing various scents into small containers. Have the participants pass around the containers and smell what is inside. The idea is to reminisce on an old memory connected to the smell inside the container. Recognizable scents such as orange slices, lemons, vanilla, coffee grounds, cooking spices, lavender, perfume, popcorn or cinnamon are just a few examples of scents that may stimulate participant's memories. Once the participant has smelled the container, ask them questions to facilitate reminiscing (i.e. Does that smell remind you of anything? Does that smell remind you of an activity you like to do?, What was your favorite thing to bake or cook? Tell me more about a time when you smelled that scent? Etc.). Items required for this activity are listed below:

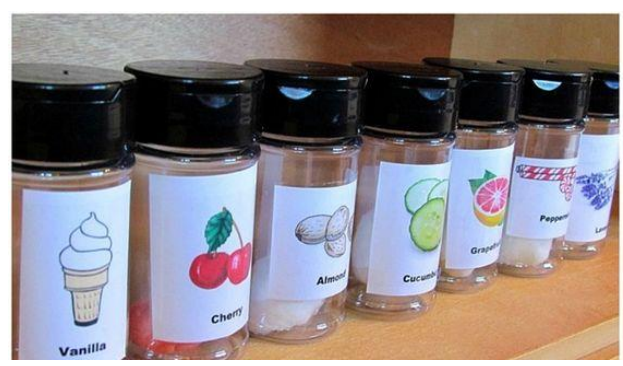

1) 5-10 Containers - Small plastic containers with lids can be purchased at a local hobby store like Michaels for \$3.99 for a pack of 4. \$7.98 total, plus tax. https://www.michaels.com/storage-cupswith-lids-by-craft-smart/10194252.html

2) Scents can be collected using common smells from fruits, spices, foods, and more. For a more sustainable, long term use option, artificial scents or essential oils can be purchased at a local hobby store like Michaels for \$3.99 for one (https://www.michaels.com/orange-fragrance-oil-by- 
ENHANCING ENGAGEMENT IN OLDER ADULTS WITH ALZHEIMER'S 60

artminds/10347567.html), or a package of three different scents for $\$ 9.99$

(https://www.michaels.com/tropical-paradise-fragrance-oil-by-artminds/10597077.html) 


\author{
Appendix $\mathrm{H}$ \\ Partner or Small Group Activities
}

*For the purpose of this project, this activity recommendation was made to an existing Glenner Town Square activity in order to maximize the increases in social participation and activity engagement of their Alzheimer's disease and dementia population. This ultimately maximizes the more immediate and practical implementation of the activity adaptation recommendations into the Glenner Town Square programming.

Park activities: Partner balloon volleyball, corn hole, bean bag tic-tac-toe, etc.

Bean bag tic-tac-toe activity: Make a large hashtag grid on the ground using tape and have the participants stand a few feet back. Taking turns, have the participant toss their color bean bag, with the goal of landing it in the square and playing tic-tac-toe with a partner or taking turns in a small group four. Participants can do this seated or standing, and it is a great way to facilitate social participation amongst participants. A list of the items needed for this activity are listed below:

1) Any colored painters tape can be used to make the tic-tac-toe grid on the ground. It can be purchased at a local hobby store like Michaels for $\$ 6.50$ for one roll. https://www.michaels.com/3m-scotchblue-painters-tape-original-multiuse/10291153.html

2) Bean bags can be reused from the corn hole game already purchased by Glenner Town Square. If new bean bags are desired, a colored bean bag set can be purchased purchased at a local hobby store like Michaels for $\$ 13.79$. https://www.michaels.com/bean-bags$\underline{\text { set/D214482S.html }}$ 


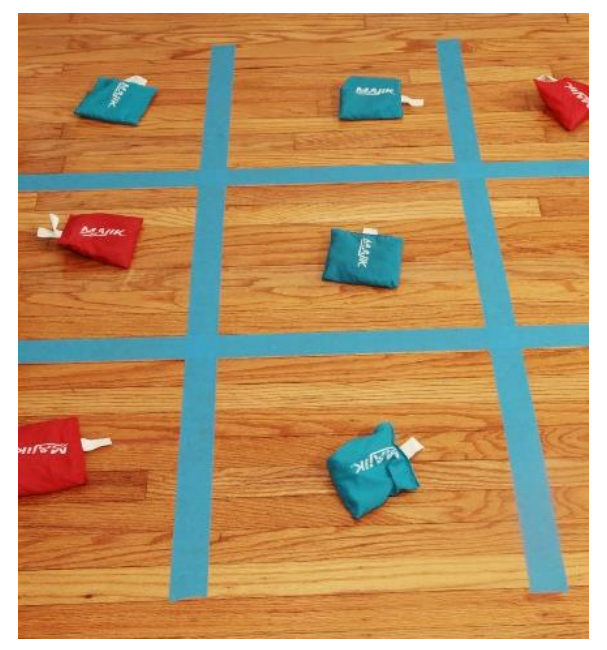

Table-top activities: tic-tac-toe, connect four, sorting activities, puzzles or matching activities.

Matching activity: During the magazine treasure hunt activity, give the participants a visual list of things to find (i.e. shoe, ball, hat, bag, animal, etc.). This can also be tailored to the participant group by pairing them up and providing magazines based on their interests (i.e. gardening, fashion, military, etc.). Then, with a partner find those items, cut them out and place them in their identified place. If finding different items and matching them to a shape or word it too difficult, try having the participants find the same item in different colors and place them in correct colored area (i.e. red dress in the red box, blue dress in the blue box). A list of the items needed for this activity are listed below:




1) Printable magazine treasure hunt activity sheets, such as the one below, can be used to facilitate the partner or small group activity. In pairs, the participants can work together to identify, cut out and place or glue the identified object next to the item on the activity sheet. Other magazine treasure hunt lists can be found online by googling magazine treasure hunt.

2) If this activity sheet is too difficult, have the participants find any items in the magazine treasure hunt by color, and match it to a near by colored bin (i.e. red car $=$ red bin). Assorted bins can be purchased at a local store such as Target for $\$ 22.99$ for six bins in assorted colors. https://www.target.com/p/ecr4kids-bendi-bin-storage-containers-withhandles-flexible-stacking-bins-for-toys-puzzles-games-and-more-6-pk/-/A-76410326

3) Participants will also need scissors to complete this activity. Craft scissors can be purchased at a local hobby store such as Michaels for $\$ 7.99$ for six pairs. https://www.michaels.com/blunt-tip-scissor-set-by-creatology/10554270.html

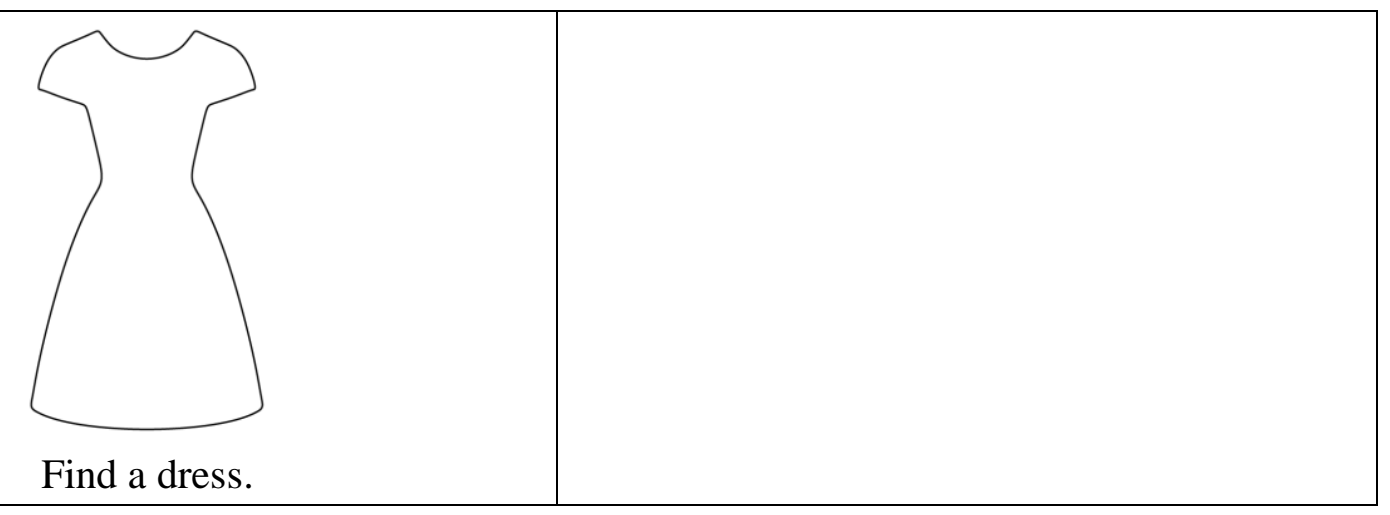


ENHANCING ENGAGEMENT IN OLDER ADULTS WITH ALZHEIMER'S 64

(n)




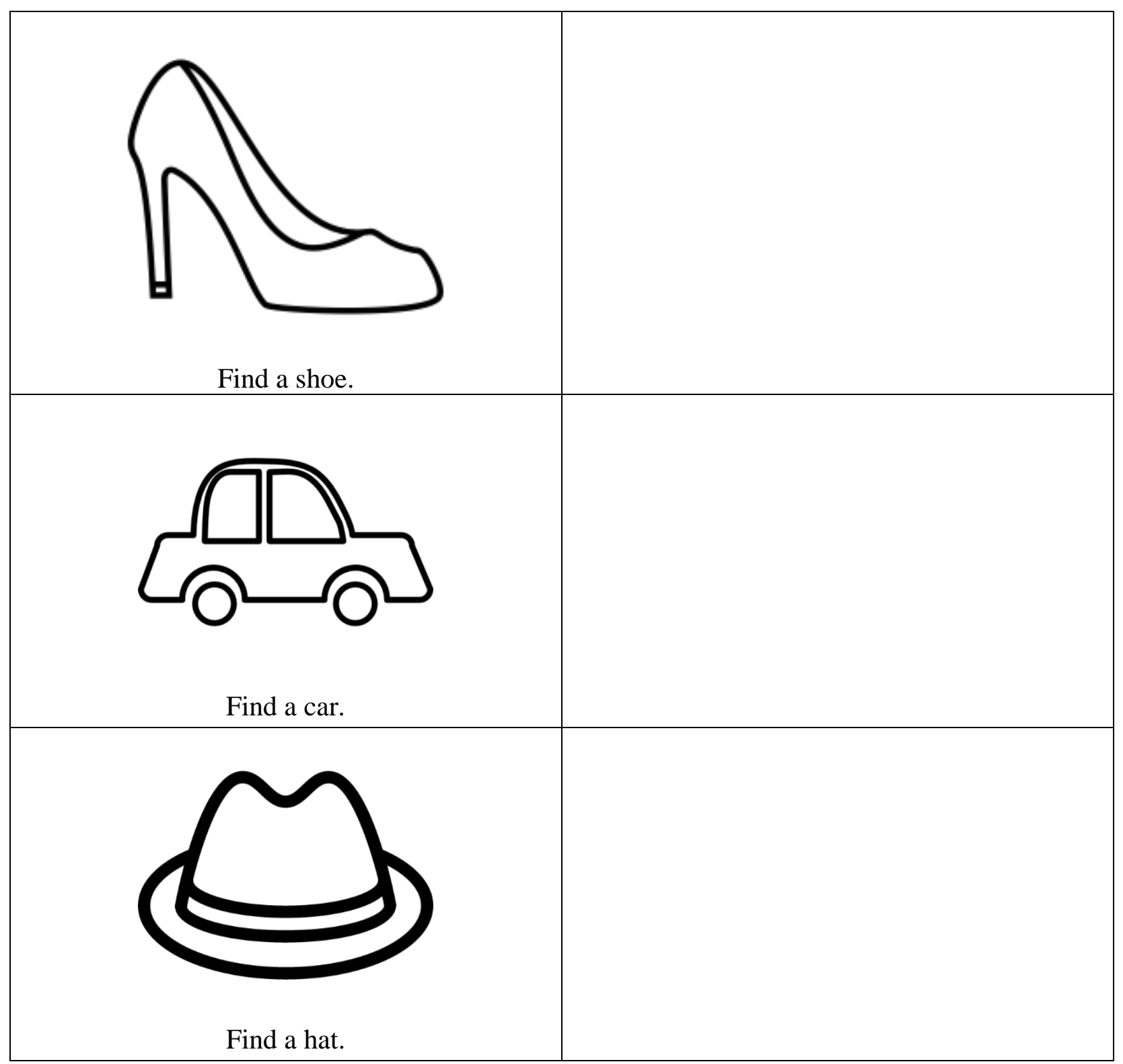

Occupation-based activities: Cooking partner activity (i.e. rolling dough and decorating), homemaking activity (i.e. sewing or quilting), art partner activities (i.e. stringing jewelry, or creating a collage), sorting household items (i.e. nail polish colors, utensils, towels or napkins, scarfs or pieces of jewelry etc.). 
Cooking partner activity: Pair up the participant's or place them in small groups of 3-4 and have them work on one cooking or baking project together. Based on the time of year, this could be a gingerbread house, or American flag cookies, etc. Each participant is creating a piece to put together as a group at the end. Small groups or partner activities provide opportunities for participants to communicate with one another and engage socially. (Based on the level of the participants, this may require some facilitation from the group leader). A list of the items needed for this activity are listed below:
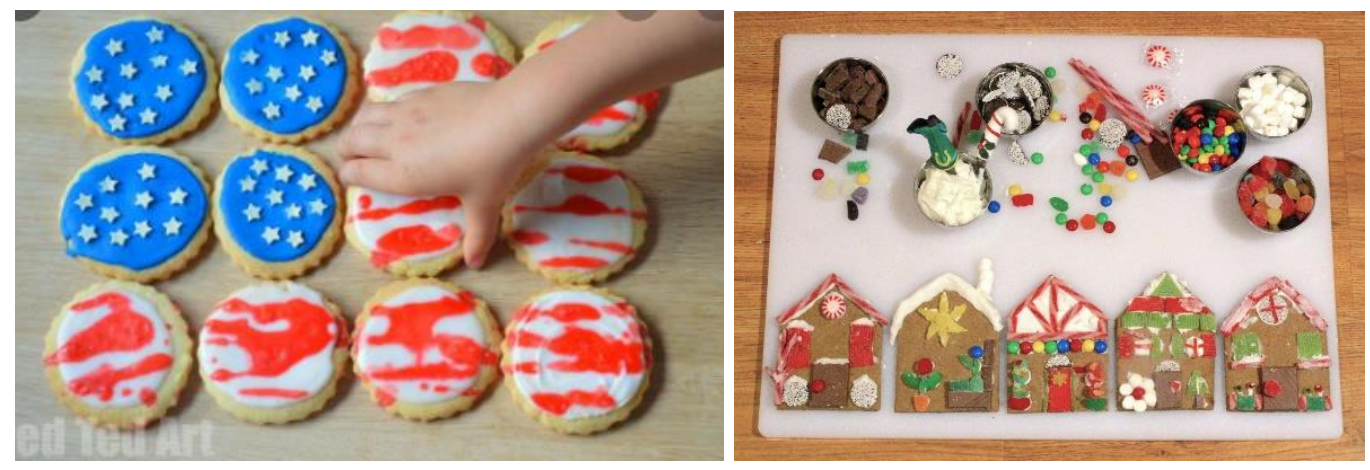

For this activity, participants will work together to create and build a themed design using cookies. Depending on the time of year, different holiday themes can be incoporated (i.e. Fourth of July flag, or a gingerbread house for christmas).

1) Blank pre-cooked sugar cookies for decorating can be purchased online for $\$ 44.95$, for 48 cookies.

https://www.foodservicedirect.com/best-maid-thaw-and-serve-sugar-cookie-2-ounce-48-per-case$\underline{21386517 . h t m l \text { ?gclid=CjwKCAjwssD0BRBIEiwA- }}$ 
$\underline{\mathrm{wE}}$

2) To decorate the cookies, frosting, sprinkles and other toppings can be purchased at the grocery store. Some suggestions include colored frosting, a variety of sprinkles, licorice, chocolate chips, butterscotch chips, Dots, and M\&M's, etc.

3) To decorate the cookies with frosting, decorating bags, bottles, and tips can be purchased at a local hobby shop like Michaels for $\$ 8.49$, which comes with two decorating tips and six disposable decorating bags. https://www.michaels.com/tri-color-decorating-set-by-celebrate$\underline{\mathrm{it} / 10404954 . \mathrm{html}}$ 


\section{Appendix I}

Schedule and Activity Routine

*For the purpose of this project, this activity recommendation was made to an existing Glenner Town Square activity in order to maximize the increases in social participation and activity engagement of their Alzheimer's disease and dementia population. This ultimately maximizes the more immediate and practical implementation of the activity adaptation recommendations into the Glenner Town Square programming.

Start the day (or first activity) with "Hello, today is Friday, March 6, 2020 and we are in Chula Vista, California. Today we are doing an art activity." Using a visual aid that mimics this information, as a visual schedule or activity calendar, like the whiteboard pictured below, can be beneficial to the participants comprehending the information. Include relevant information such as the date, where they are, and what they will be doing.

\section{Today is: March 6, 2017}




\section{Appendix $\mathbf{J}$}

Table Top Social Participation Activities

Picture or Item Examples: Small pictures of famous people from the 50's or 60's, a picture of a well-known car, or the poster of a movie from that era, etc. Pictures can be found on the internet and laminated for easy reuse. More resources for item suggestions can be found on fiftiesweb.com.

Lucille Ball Elvis Presley $\quad$ Frank Sinatra Singing in the Rain - 1952
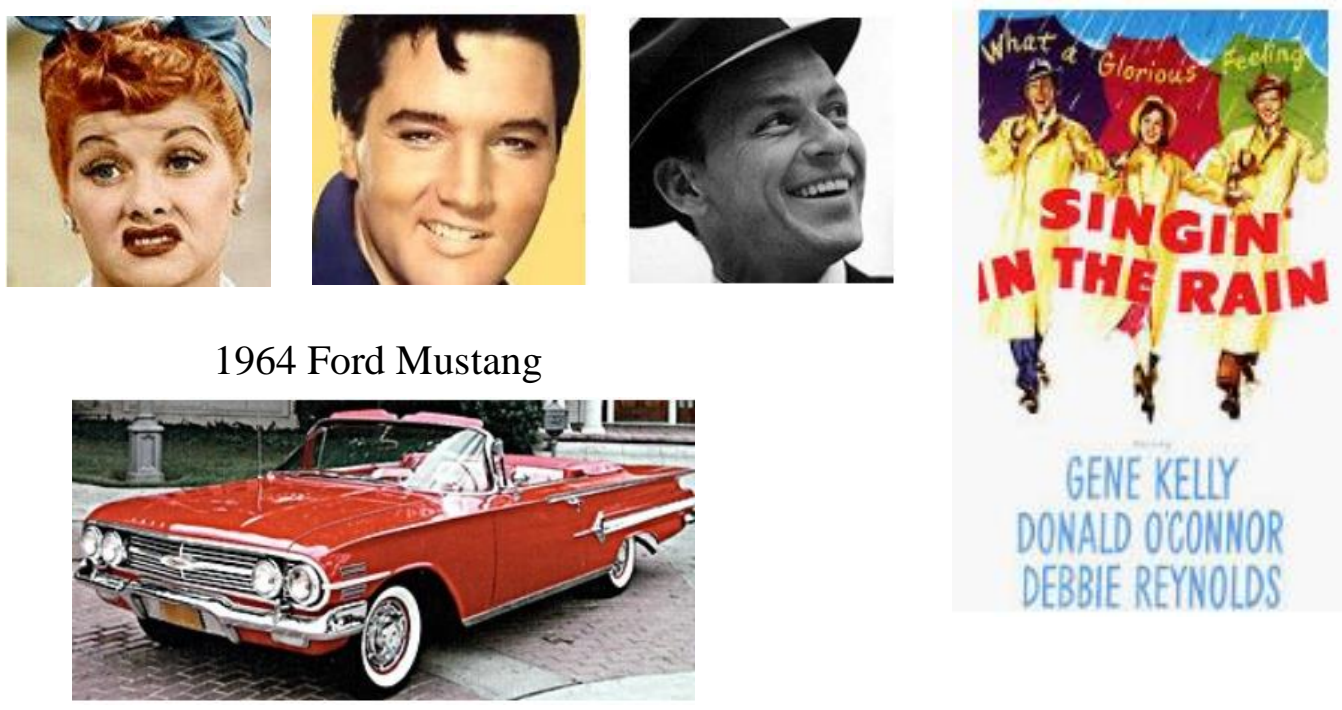


\section{Appendix K}

\section{Caregiver Take Home Report}

A simple way to incorporate this would be sending an email at the start of the week providing a copy of the activities schedule for the group the participant is in. For example, please see the following:

Aces - Week of April 6 - April10

\begin{tabular}{|l|l|l|l|l|l|}
\hline & Monday & Tuesday & Wednesday & Thursday & Friday \\
\hline 8:00-9:00 & Breakfast & Breakfast & Breakfast & Breakfast & Breakfast \\
\hline 9:00- & Floral & Postcards to & Puzzles & Titanic & Magazine \\
\hline 10:00 & Arrangements & the Troops & & & Treasure \\
11:00 & Trivia & Poker & I Love Lucy & T-Bird Tales & Readers \\
\hline 11:00- & Lunch & Lunch & Lunch & Lunch & Theater \\
\hline 12:00 & & & & & \\
\hline
\end{tabular}

Schedules and activities will vary based on which group the participant is a part of during their week at Glenner Town Square. 
ENHANCING ENGAGEMENT IN OLDER ADULTS WITH ALZHEIMER'S 71

\section{Appendix L}

Ongoing Education Opportunities

Available Resources: The Alzheimer's Association - San Diego Branch has a wide variety of classes, trainings and workshops available for caregivers for individuals with dementia.

Providing continuing education opportunities for staff could be beneficial to providing the upmost care for the participants at Town Square. Please use the link below to find the available classes (https://www.alz.org/help-support/resources/care-training-resources).

Further, education based training for the staff which was developed by an occupational therapist would be beneficial to continue building on the staff's current understanding of the participants, the current activities, how to adapt an activity to meet the "just right challenge", or how to incorporate meaningful occupation in order to increase their activity engagement and social participation. 